NIST Technical Note 1789

\title{
Validation Testing of Standard Requirements for Backpack-type Radiation Detectors
}

L. Pibida

B. Norman

http://dx.doi.org/10.6028/NIST.TN.1789

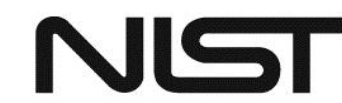

National Institute of Standards and Technology U.S. Department of Commerce 


\title{
NIST Technical Note 1789
}

\section{Validation Testing of Standard Requirements for Backpack-type Radiation Detectors}

\author{
L. Pibida \\ B. Norman
}

Radiation and Biomolecular Physics Division

Physical Measurement Laboratory

http://dx.doi.org/10.6028/NIST.TN.1789

March 2013

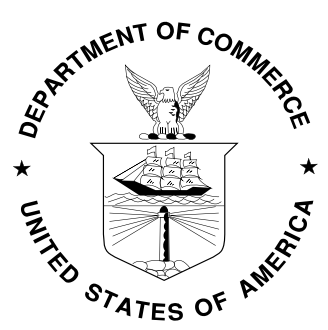

U.S. Department of Commerce Rebecca Blank, Acting Secretary

National Institute of Standards and Technology Patrick D. Gallagher, Under Secretary of Commerce for Standards and Technology and Director 
Certain commercial entities, equipment, or materials may be identified in this document in order to describe an experimental procedure or concept adequately. Such identification is not intended to imply recommendation or endorsement by the National Institute of Standards and Technology, nor is it intended to imply that the entities, materials, or equipment are necessarily the best available for the purpose.

National Institute of Standards and Technology Technical Note 1789

Natl. Inst. Stand. Technol. Tech. Note 1789, 39 pages (March 2013) http://dx.doi.org/10.6028/NIST.TN1789

CODEN: NTNOEF 


\title{
Validation Testing of Standard Requirements for Backpack-type Radiation Detectors
}

\author{
L. Pibida and B. Norman \\ National Institute of Standards and Technology, Gaithersburg, MD 20899-8462
}

\begin{abstract}
Two gross count and one radionuclide identification backpack-type radiation detectors (BRDs) were used to validate radiological test requirements listed in the Domestic Nuclear Detection Office (DNDO) Technical Capability Standard (TCS) for BRDs. For this purpose, a linear motion system was used to simulate the relative movement between the backpacks and the radioactive sources. Data was analyzed to evaluate the standard requirements for this type of instrument. It was observed that applying a scaling factor to the testing distance (equivalent to changing the testing radiation field) based on the measured background radiation can carry a large uncertainty as the measured values will strongly depend on the instrument used to perform the measurement. Therefore, testing parameter might not be reproduced in different laboratories. The emission rate and testing distance defined in the BRD TCS for the ${ }^{252} \mathrm{Cf}$ source seems to be close to the limit of detection for this type of instrument. The fluence rate values produced by the different gamma-ray emitting sources required for testing the BRDs seem appropriate. If required to be closer to the limit of detection of the BRDs, the fluence rate values could be further reduced.
\end{abstract}

Key words: gamma-ray detection, neutron detection, backpack-type radiation detectors, standard validation.

\section{Introduction}

Backpacks containing radiation detectors are used for localization of radioactive sources in a variety of areas, from buildings to ships. Several government agencies (Federal, State, and Local) have acquired different backpack-type radiation detectors (BRDs) for detection and interdiction of radioactive and nuclear materials. In general, there are two different types of backpacks currently available: one with gross count gamma-ray detection capabilities and the other with additional radionuclide identification capabilities with optional neutron detection. The Technical Capability Standard (TCS) document addresses both types of BRDs. While this standard was written primarily to address government needs, it requires validation based on testing of commercially available instruments. This work covers testing of the main parameters and requirements discussed by the TCS working group during the document standard development.

The following tests were performed to assess the TCS document requirements: 
- Scaling of source emission with gamma-ray and neutron background measurement at test location

- BRD response as a function of increasing gamma-ray background level

- Suitability of fluence rate values used for testing BRDs

- Calculations of emission rates and/or fluence rate for SNM and DU sources

- Neutron measurement requirements

The results of these measurements were used to modify the test requirements and associated test methods of the draft version of the TCS document in order to produce the final version of the TCS document.

\section{Experimental setup}

Two gross count BRDs and one radionuclide identification BRD were used to validate a subset of the radiological test requirements listed in the TCS document standard. In this work, testing parameters used to assess the applicability of the requirements for the BRDs were broader than those specified by the TCS standard. The measurements were designed to assess the validity of the test methods and requirements described in the TCS and not to assess the goodness of the individual BRD response.

Backpacks were placed on an aluminum stand with the center line of the backpack located $1.2 \mathrm{~m}$ from the floor. The backpacks were positioned with the front face at several fixed distances from a horizontal track along which radioactive sources could move past the backpacks. All sources were transported along the track in front of the backpacks at two different speeds of $1.2 \mathrm{~m} / \mathrm{s}$ and $2.2 \mathrm{~m} / \mathrm{s}$. The source was transported past the backpacks at a height of $1.2 \mathrm{~m}$ from the floor. These tests were performed with the front of the BRD facing the source (referred to as the "Front" position) as it would be worn in the field (the backpack straps were facing away from the source). Measurements were performed without and with a phantom. In the latter case, the backpack was mounted with the back against the phantom to mimic the presence of a human body, see Figure 1. For each source different combinations of distance, speed and height were selected. At least 10 measurements were repeated for each source and for each setting combination. 


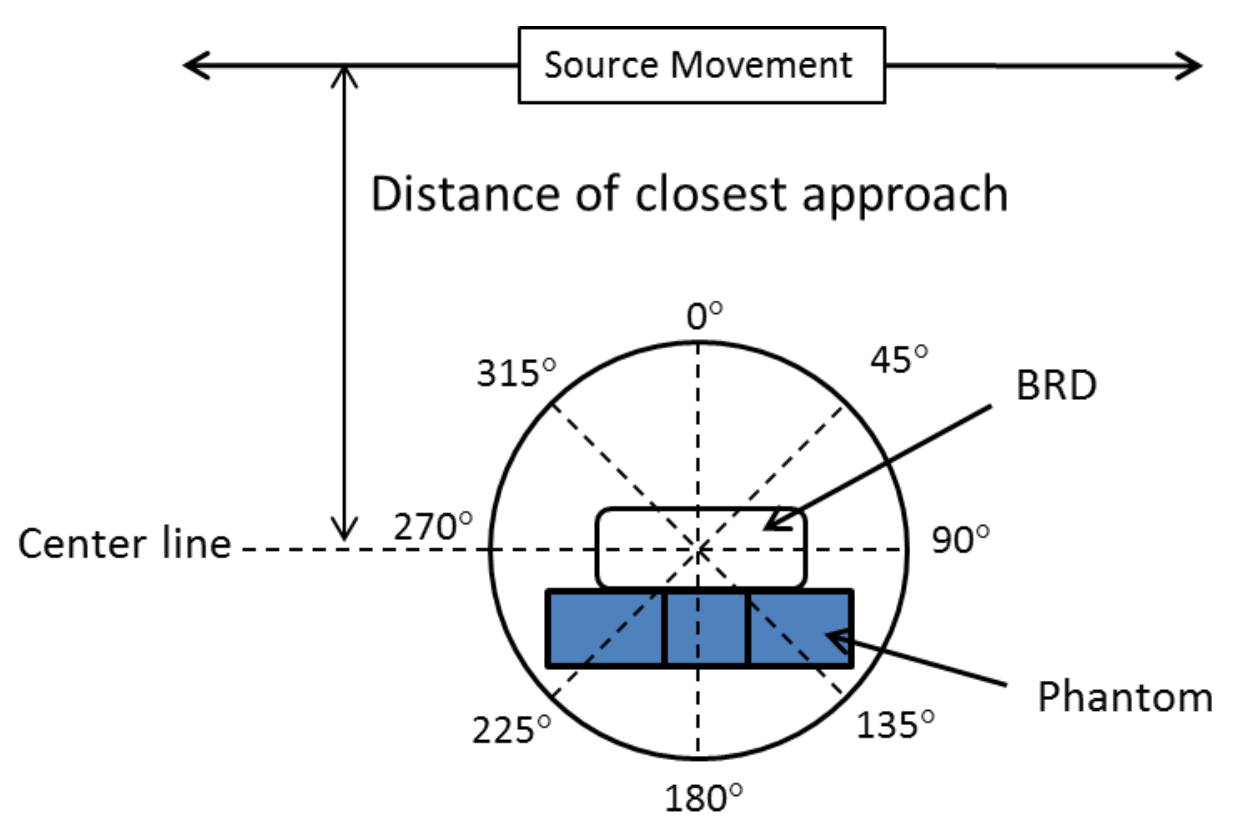

Figure 1: Diagram of BRD and phantom mounting

As this type of instrument is designed to be carried on a person's back, tests were performed both without a phantom and with two different types of phantoms (especially for the neutron tests). One phantom was a cubic-shaped block filled with water with dimensions of $30 \mathrm{~cm}$ High $(\mathrm{H}) \times$ $30 \mathrm{~cm}$ Long $(\mathrm{L}) \times 15 \mathrm{~cm}$ Wide $(\mathrm{W})$ and made of polymethyl methacrylate (PMMA), with a mass density, $\rho$, of $\rho=1.19 \mathrm{~g} / \mathrm{cm}^{3}$. The other phantom was a cubic-shaped block $(40 \mathrm{~cm}(\mathrm{H}) \times 40 \mathrm{~cm}$ $(\mathrm{L}) \times 15 \mathrm{~cm}(\mathrm{~W})$ ), made out of solid PMMA. Some standards do not require the use of phantoms when testing with gamma-ray emitting sources, phantoms are only required when testing with neutron sources. To investigate the difference in the gamma-ray response of the BRDs tests were carried out with and without phantoms.

Table 1 shows the activities for the gamma-ray and neutron sources used for testing. These radionuclides were selected to test the energy range covered by the TCS document. As can be observed in Table 1, some of the sources used in this work have activities that are different than the ones proposed in the TCS document standard. These additional sources were used exclusively to test the detection limits in addition to the TCS requirements for the backpacks. For the neutron tests, two different sources were used. One was a ${ }^{252} \mathrm{Cf}$ source with an emission rate of $2 \times 10^{4}$ neutrons per second placed inside a $1 \mathrm{~cm}$ steel encapsulation. The second one was a ${ }^{252} \mathrm{Cf}$ source with an emission rate of $4.2 \times 10^{5}$ neutrons per second placed inside a thin aluminum encapsulation and moderated by a $2 \mathrm{~cm}, 4 \mathrm{~cm}$ or $8 \mathrm{~cm}$ thick high density polyethylene (HDPE) sphere as well as a $5 \%$ borated $8 \mathrm{~cm}$ thick HDPE sphere. This shielding was not specified by the standard, it was used to assess differences in detection for additional neutron moderation. Table 1 also lists the calculated fluence rate, $\phi$, using equation (1) with a cut-off energy of $40 \mathrm{keV}$, these values were obtained using the gamma-ray emission probabilities listed in reference [6].

$$
\phi=\frac{A}{4 \pi r^{2}} \sum_{i} p\left(E_{i}\right)
$$


where $p(E)$ is the emission probability of a gamma-ray at energy $E, A$ is the source activity, and $r$ is the radius of the sphere from the point source.

Table 1: Activity values for gamma-ray and neutron sources

\begin{tabular}{|c|c|c|}
\hline Radionuclide & $\begin{array}{c}\text { Activity }(\mathbf{k B q}) / \text { Emission } \\
\text { rate }\end{array}$ & $\begin{array}{c}\text { Calculated fluence rate } \\
\left(\text { photons } / \mathrm{s} / \mathrm{cm}^{2}\right) \text { at } 2 \mathrm{~m} \text { (cut-off } \\
\text { energy } 40 \mathrm{keV})\end{array}$ \\
\hline${ }^{241} \mathrm{Am}$ & 1890 & 1.35 \\
\hline${ }^{133} \mathrm{Ba}$ & 508 & 1.38 \\
\hline${ }^{57} \mathrm{Co}$ & 674 & 1.29 \\
\hline${ }^{60} \mathrm{Co}$ & 1480 & 5.87 \\
\hline${ }^{137} \mathrm{Cs}$ & 504 & 0.85 \\
\hline DU & $\begin{array}{c}630 \mathrm{~g} \\
\left(\text { surface area } 100 \mathrm{~cm}^{2}\right)\end{array}$ & $\begin{array}{c}0.08 \\
\text { (for } 1.001 \mathrm{MeV} \text { line) }\end{array}$ \\
\hline${ }^{237} \mathrm{~Np}$ & $2540(\sim 90 \mathrm{mg})$ & 3.76 \\
\hline${ }^{226} \mathrm{Ra}$ & 294 & 4.87 \\
\hline${ }^{232} \mathrm{U}$ & 694 & 10.5 \\
\hline${ }^{252} \mathrm{Cf}^{\dagger}$ & $2 \times 10^{4}$ neutrons/s & - \\
\hline${ }^{252} \mathrm{Cf}^{*}$ & $4.2 \times 10^{5}$ neutrons/s & - \\
\hline \multicolumn{3}{|c|}{$\begin{array}{l}\text { The uncertainty in the activities and neutron emission rate is } 10 \% \text {, assuming a coverage factor of }(\mathrm{k}=1) \text {. } \\
\text { The activity values shown in the table are the ones used at the time of the measurements. } \\
{ }^{\dagger} \text { The } 2 \times 10^{4} \text { neutrons } / \mathrm{s}^{252} \mathrm{Cf} \text { source was shielded by } 1 \mathrm{~cm} \text { of steel, the gamma-ray emission of this source was } \\
\text { very low so there was no need to add the lead shielding for the neutron tests. } \\
\text { * The } 4.2 \times 10^{5} \text { neutrons } / \mathrm{s}^{252} \mathrm{Cf} \text { source was considered a bare source; it was placed inside a } 0.762 \mathrm{~mm} \text { thick } \\
\text { aluminum holder. }\end{array}$} \\
\hline
\end{tabular}

For these tests, the backpacks are referred to as BRD-1, BRD-2 and BRD-3. The BRD's characteristics are listed in Table 2. The backpack's alarm thresholds used during testing were the default values set by the manufacturers.

Table 2: General characteristics of backpacks used in tests

\begin{tabular}{|c|c|c|c|}
\hline Characteristics & BRD-1 & BRD-2 & BRD-3 \\
\hline $\begin{array}{l}\text { Gamma-ray detector } \\
\text { type }\end{array}$ & Six CsI scintillators & $\begin{array}{l}\text { Plastic scintillator (PVT), } \\
\text { Geiger-Muller GM) } \\
\text { gamma-ray detector, } \\
\text { NaI(Tl) detector }\end{array}$ & $\begin{array}{l}\text { One plastic scintillator } \\
\text { (Natural Background } \\
\text { Rejection }[\mathrm{NBR}] \text {-detector) }\end{array}$ \\
\hline $\begin{array}{l}\text { Gamma-ray detector } \\
\text { dimensions }\end{array}$ & $\begin{array}{l}\text { Four modules facing back: } \\
\text { Diameter }=1.3 \mathrm{~cm} \\
\text { Length }=3.8 \mathrm{~cm} \\
\text { Two modules facing } \\
\text { sideways: } \\
\text { Diameter }=1.3 \mathrm{~cm} \\
\text { Length }=3.8 \mathrm{~cm}\end{array}$ & $\begin{array}{l}\text { Plastic scintillation (PVT) } \\
147 \mathrm{~cm}^{2} \text { active area. } \\
\text { NaI }(\mathrm{Tl}) \text { detector: } \\
\text { Diameter }=5 \mathrm{~cm} \\
\text { Length }=5 \mathrm{~cm}\end{array}$ & $\begin{array}{l}\text { Volume } \sim 770 \mathrm{~cm}^{3} \\
\text { Diameter }=9 \mathrm{~cm} \\
\text { Length }=12 \mathrm{~cm} \\
5.08 \mathrm{~cm} \text { diameter PMT tube }\end{array}$ \\
\hline Neutron detector type & Seven ${ }^{3} \mathrm{He}$ tubes & ${ }^{3}$ He detector & Two ${ }^{3} \mathrm{He}$ tubes \\
\hline $\begin{array}{l}\text { Neutron detector } \\
\text { dimensions }\end{array}$ & $\begin{array}{l}\text { Diameter }=5.08 \mathrm{~cm} \\
\text { Length }=35.81 \mathrm{~cm} \\
\text { Tube pressure: } 270.89 \mathrm{kPa} \\
(39.3 \text { psi })\end{array}$ & $\begin{array}{l}\text { Information not provided } \\
\text { in instrument manual }\end{array}$ & $\begin{array}{l}\text { Diameter }=5.08 \mathrm{~cm} \text { Length } \\
=35.56 \mathrm{~cm} \\
\text { Tube pressure: } 250 \mathrm{kPa} \\
(36.27 \mathrm{psi})\end{array}$ \\
\hline Display & $\begin{array}{l}5.7 \mathrm{~cm} \times 5.7 \mathrm{~cm} \mathrm{LCD} \\
\text { display with backlight } \\
\text { Provides: } \\
\text { Gamma-ray and neutron }\end{array}$ & $\begin{array}{l}\text { Wrist mounted LCD } \\
\text { backlight display } \\
\text { Provides: } \\
\text { Gamma-ray and neutron }\end{array}$ & $\begin{array}{l}\text { LEDs for gamma-ray and } \\
\text { neutron detection. Provides: } \\
\text { LEDs for gamma-ray and } \\
\text { neutron signal level (scale } 1\end{array}$ \\
\hline
\end{tabular}




\begin{tabular}{|c|c|c|c|}
\hline Characteristics & BRD-1 & BRD-2 & BRD-3 \\
\hline & $\begin{array}{l}\text { count rate, gamma-ray and } \\
\text { neutron alarm level, } \\
\text { gamma-ray and neutron } \\
\text { alarm trip level, active plot } \\
\text { of gamma-ray and neutron } \\
\text { alarm level versus time and } \\
\text { operating status. }\end{array}$ & $\begin{array}{l}\text { count rate, gamma-ray and } \\
\text { neutron alarm level, } \\
\text { gamma-ray and neutron } \\
\text { alarm, active plot of } \\
\text { gamma-ray and neutron } \\
\text { count rate versus time, } \\
\text { exposure rate, battery life } \\
\text { and radionuclide } \\
\text { identification, including } \\
\text { confidence indication. }\end{array}$ & $\begin{array}{l}\text { to } 10) \text {, gamma-ray and } \\
\text { neutron alarm acknowledge, } \\
\text { LEDs for artificial and natural } \\
\text { radiation. Manual provides a } \\
\text { conversion table for the LED } \\
\text { display in mrem/h or } \mu \mathrm{Sv} / \mathrm{h} \\
\text { for gammas and in counts per } \\
\text { second for neutrons. }\end{array}$ \\
\hline Battery life & $\begin{array}{l}40 \text { hours (without } \\
\text { backlight) replaceable } \\
\text { battery. }\end{array}$ & $\begin{array}{l}9 \text { hours to } 20 \text { hours } \\
\text { rechargeable battery pack. }\end{array}$ & $\begin{array}{l}60 \text { hours to } 70 \text { hours } \\
\text { rechargeable battery pack. }\end{array}$ \\
\hline $\begin{array}{l}\text { Gamma-ray alarm } \\
\text { threshold }\end{array}$ & $\begin{array}{l}4 \text { standard deviations from } \\
\text { background }\end{array}$ & $\begin{array}{l}\text { Different values for the } \\
\text { different displayed levels. } \\
\text { Level } 1 \text { is } 4.3 \text { sigma from } \\
\text { background }\end{array}$ & $\begin{array}{l}5 \text { standard deviations from } \\
\text { background }\end{array}$ \\
\hline
\end{tabular}

The BRDs have different types of displays. Therefore, based on the BRDs display capabilities the following displayed parameters were recorded for the measurements:

- BRD-1

- Gamma-ray level (unit-less display from 0 to 9)

- Neutron level (unit-less display from 0 to 9)

- Gamma-ray count rate readings (unit = counts per second $(\mathrm{cps})$ )

$\circ$ Neutron count rate readings (unit $=$ counts per second $(\mathrm{cps})$ )

- BRD-2

○ Gamma-ray level (unit-less display from 0 to 9 )

- Neutron level (unit-less display from 0 to 9)

- Gamma-ray count rate readings (unit = counts per second $(\mathrm{cps})$ )

$\circ$ Neutron count rate readings (unit $=$ counts per second $(\mathrm{cps})$ )

$\circ$ Radionuclide identification

- BRD-3

- Gamma-ray level (unit-less display from 1 to 10, and 0 corresponds to no LED illuminated)

- Neutron level (unit-less display from 1 to 10, and 0 corresponds to no LED illuminated)

Two gamma-ray handheld instruments were used to measure the background and source exposure rate (in units of roentgen) ${ }^{1}$ and dose equivalent rates (in units of Sv). The gamma-ray ambient dose equivalent rate $\left(\dot{H}^{*}(10)\right)$ and exposure rate was measured using the Victoreen

\footnotetext{
${ }^{1}$ NIST does not endorse the use of non-SI units. This paper uses non-SI units because it addresses the requirements listed in the TCS published standards and the units displayed by the test equipment. $1 \mathrm{R}=2.58 \times 10^{-4} \mathrm{C} / \mathrm{kg}$.
} 
451P-DE-SI-RYR ${ }^{2}$ and the Thermo FH40G-L respectively. The Thermo unit allows for integration of the gamma-ray field reducing the uncertainty in the background exposure rate measurements. The neutron measurements were performed using the Thermo Eberline ASP 2e neutron handheld survey meter.

\section{Results and discussions}

\subsection{Scaling of source emission with gamma-ray and neutron background measurement at the test location}

Different Department of Energy (DOE) testing programs make use of scaling rules to determine the appropriate value of the source activity or source emission rate to be used in testing grosscount radiation portal monitors. These scaling rules allow adjusting the source activity or fluence rate according to the gamma-ray or neutron background radiation levels present at the location were the test is being conducted. The need for this adjustment or scaling of the source activity or emission rate results from the fact that:

- The instrument minimum detection limit depends on the radiation background at the location.

- The gross-count radiation portal monitors alarm threshold is calculated as a multiple of the square root of the background radiation level ( $n \sqrt{\text { Background radiation level }})$.

- The sources used for testing produce radiation fields are close to background levels.

The use of these scaling rules ensures that the same minimum level of detection performance is met for gross-count portal monitors across different testing locations, only for monitors that calculate the alarm threshold as a multiple of the square root of the background radiation level. Furthermore, this guaranties that the same number of gamma-rays or neutrons are measured above background.

During the development of the BRD TCS the applicability of these scaling rule methods for the testing of BRDs was discussed. The BRD TCS specifies the fluence rate of the testing sources instead of their activities or emission rates. This allows the use of any source quantity and shape as long as it produces the required fluence rate at the location of the instrument under test. Therefore, when specifying the source fluence rate for a given test condition, the background radiation level scaling methods (for a given source quantity) will be applied to the source-todetector distance.

If the BRD does not set the alarm threshold as a multiple of the square root of the background radiation level, then the use of the scaling rule would adversely affect the results of the test. It is important to specify the range of the source activity, fluence rate or exposure rate for which this scaling rule is valid. In order to reduce the uncertainty determination of the testing radiation field, this scaling rule should not be applied to large radiation sources producing a field more than 100 times larger than background levels.

\footnotetext{
${ }^{2}$ Mention of commercial products does not imply recommendation nor endorsement by the National Institute of Standards and Technology, nor does it imply that the products identified are necessarily the best available for the purpose.
} 
During the BRD TCS document development, it was suggested that the testing fluence rate values for all the sources were specified at a reference background radiation level of $20 \mu \mathrm{R} / \mathrm{h}$. It was proposed that if testing is performed at a different facility or location where the background radiation level is lower than the reference value of $20 \mu \mathrm{R} / \mathrm{h}$ the testing distance, $d$, shall be scaled by the square root of the ratio of the background radiation levels at both facilities. Scaling the distance in this way will adjust the fluence rate (above background) delivered to the detector so that the sensitivity of the instrument under test is approximately the same at any facility regardless of changes in radiation background levels (from the specified reference value of $20 \mu \mathrm{R} / \mathrm{h})$.

As an illustration of the implementation of the scaling rule, consider a test being performed at a facility were the gamma-ray background radiation level is $10 \mu \mathrm{R} / \mathrm{h}$. In order to ensure that the fluence rate (above background) delivered to the detector at this facility is the same as the fluence rate delivered at a different testing facility were the background level is $20 \mu \mathrm{R} / \mathrm{h}$, the source-to-detector distance needs to be scaled as follows:

$$
d(10 \mu R / h)=d(20 \mu R / h) \frac{\sqrt{20 \mu R / h}}{\sqrt{10 \mu R / h}}
$$

where $d(10 \mu \mathrm{R} / \mathrm{h})$ and $d(20 \mu \mathrm{R} / \mathrm{h})$ are the source-to-detector distances at a laboratory where the radiation background are $10 \mu \mathrm{R} / \mathrm{h}$ and $20 \mu \mathrm{R} / \mathrm{h}$ respectively. Table 3 lists the distance at which the detector should be placed from a gamma-ray source for a test conducted at 3 different locations each with a different radiation background level of $5 \mu \mathrm{R} / \mathrm{h}, 10 \mu \mathrm{R} / \mathrm{h}$ and $20 \mu \mathrm{R} / \mathrm{h}$. In Table 3 the testing distances for background levels of $5 \mu \mathrm{R} / \mathrm{h}$ and $10 \mu \mathrm{R} / \mathrm{h}$ were derived from the distance of $1.5 \mathrm{~m}$ specified for the reference background value of $20 \mu \mathrm{R} / \mathrm{h}$ as described in the TCS document. Similarly, the scaling rule followed for neutron sources is the same as for gamma-ray sources given by Equation 1. Table 3 also shows testing distances for a neutron source placed in a location with three possible neutron background levels of 150 neutrons s $\mathrm{m}^{-2}$, 300 neutrons $\mathrm{s}^{-1} \mathrm{~m}^{-2}$ and 600 neutrons $\mathrm{s}^{-1} \mathrm{~m}^{-2}$.

The scaling rule, from Equation 1, used to adjust the testing distances to account for the different possible background radiation levels results in differences in the fluence rate of up to $30 \%$. The determination of the background level at different laboratories can be performed using different types of radiation detection instruments. This adds an additional variable to the scaling process, as differences in the background determination (in a given location), when using different types of instruments, can be larger than $30 \%$.

Table 3: Example of testing distance, $d$, for different radiation background levels

\begin{tabular}{|c|c|c|c|}
\hline Source & $\begin{array}{c}\text { Radiation } \\
\text { Type }\end{array}$ & $\begin{array}{c}\text { Background } \\
\text { Level }\end{array}$ & $\begin{array}{c}\text { Testing } \\
\text { Distance (m) }\end{array}$ \\
\hline \multirow{3}{*}{${ }^{237} \mathrm{~Np}$} & \multirow{3}{*}{ Gamma rays } & $20 \mu \mathrm{R} / \mathrm{h}$ & $\begin{array}{c}1.5 \\
\text { (reference value) }\end{array}$ \\
\hline & & $10 \mu \mathrm{R} / \mathrm{h}$ & $\begin{array}{c}2.1 \\
\text { (scaled value) }\end{array}$ \\
\hline & & $5 \mu \mathrm{R} / \mathrm{h}$ & $\begin{array}{c}3.0 \\
\text { (scaled value) }\end{array}$ \\
\hline${ }^{252} \mathrm{Cf}$ & Neutrons & 600 neutrons $\mathrm{s}^{-1} \mathrm{~m}^{-2}$ & $\begin{array}{c}1.0 \\
\text { (reference value) }\end{array}$ \\
\hline
\end{tabular}




\begin{tabular}{|c|c|c|c|}
\hline & 300 neutrons $\mathrm{s}^{-1} \mathrm{~m}^{-2}$ & $\begin{array}{c}1.4 \\
\text { (scaled value) }\end{array}$ \\
\cline { 3 - 4 } & & $\begin{array}{c}2.0 \\
\text { (scaled value) }\end{array}$ \\
\hline
\end{tabular}

To investigate the applicability of the proposed scaling method several measurements were performed to validate the requirements. Radiation background measurements were performed in two different locations at NIST using different types of instruments to evaluate the reproducibility in the determination of the gamma-ray exposure rate.

The measurements of the gamma-ray radiation background at location 1 performed under the same conditions on the same day using the two handheld instruments are shown in Figure 2. The average dose equivalent rate and exposure rate values measured with each of these instruments were:

- Ambient dose equivalent rate (Victoreen 451P-DE-SI-RYR) $=0.057 \mu \mathrm{Sv} / \mathrm{h} \pm 42 \%$ (1 standard deviation)

- Exposure rate (Thermo FH40G-L) $=10.14 \mu \mathrm{R} / \mathrm{h} \pm 10 \%$ ( 1 standard deviation). The average was obtained from 20300 -s integrated exposure values. Exposure rate values were divided by a factor of 100 in order to plot them together with the Victoreen 451P-DE-SI-RYR measured ambient dose equivalent rate values.

The determination of the background ambient dose equivalent rate using the Victoreen 451P-DESI-RYR was performed by taking 20 independent dose equivalent rate readings (each independent reading consists of the average obtained from recording 10 displayed values). The determination of the background exposure rate using the Thermo FH40G-L was performed by taking 20 independent exposure readings integrated over $300 \mathrm{~s}$. The uncertainties are the standard deviation of the 20 readings (1-standard deviation). The difference in the background determination using these two instruments is approximately $78 \%$. 


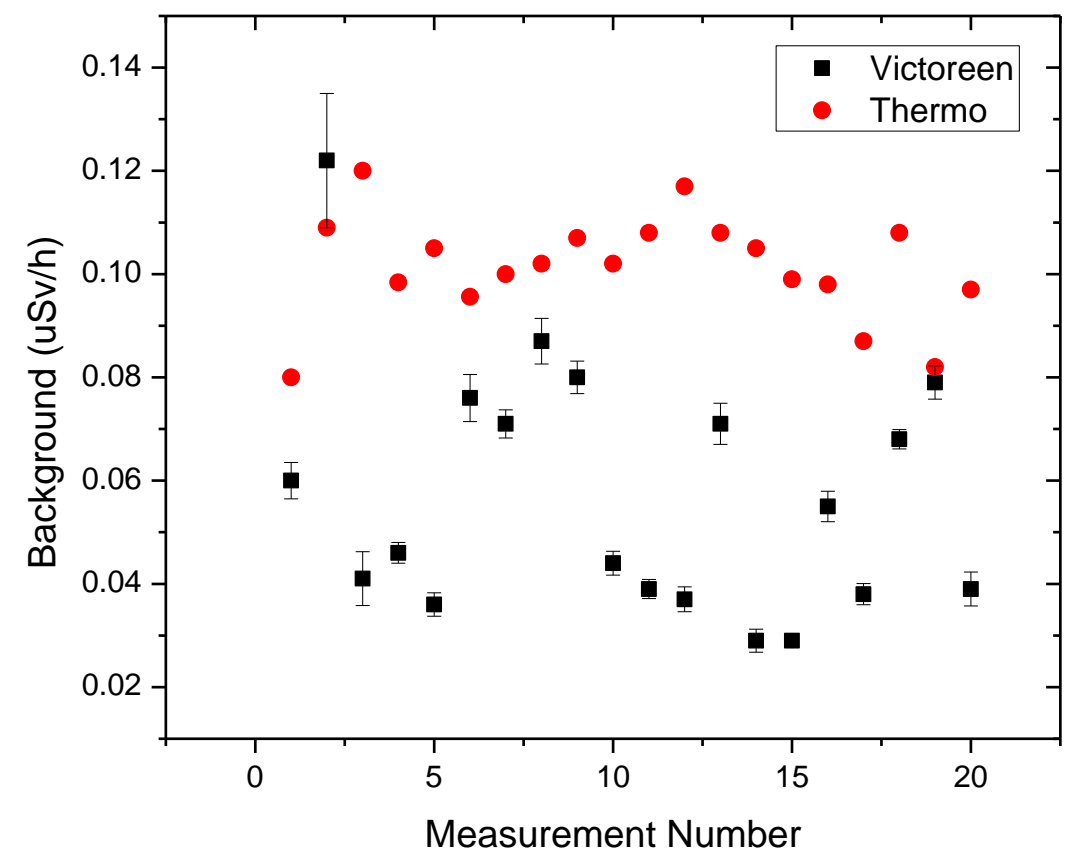

Figure 2: Background exposure rate measurement in location 1 using different instruments; uncertainties are 1-standard deviation.

Figure 3 shows measurements of the gamma-ray radiation background at location 2 performed under the same conditions over several years using five different ionization chambers. 


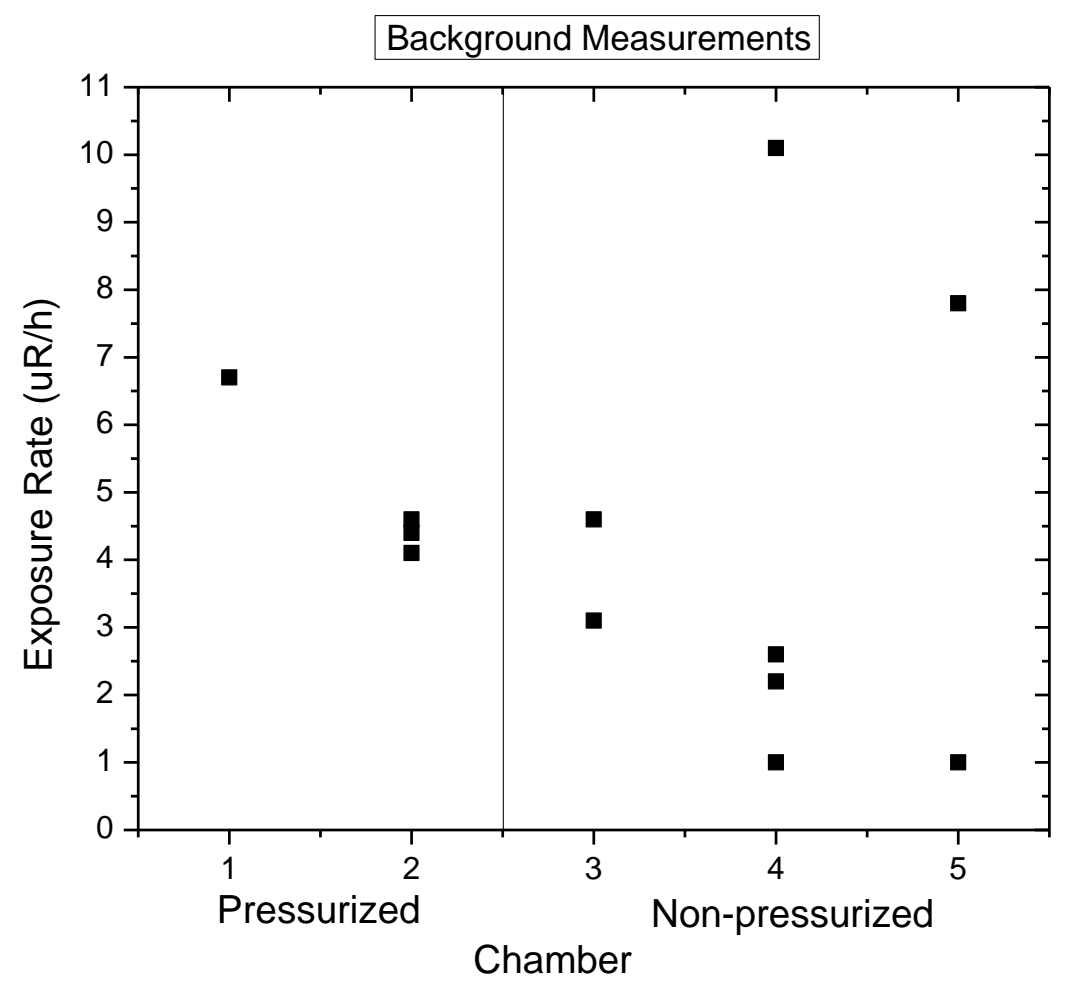

Figure 3: Background exposure rate measurement in location 2 using five different ionization chambers. Uncertainties are smaller than the size of the symbol; uncertainties are 1-standard deviation.

The variability in the background exposure rate determination through an extended period of time using the same pressurized chamber is small. As expected when using a non-pressurized ionization chamber this variation is large. The variability in the determination of the background exposure rate measurements using different types of ionization chambers is very large, including the pressurized chamber where there is a difference of approximately $44 \%$. Due to this large variability it would not possible to accurately determine the source scaling factor for testing at different locations with different background levels when using different instruments to determine the gamma-ray radiation background.

\subsection{BRD response as a function of increasing gamma-ray background level}

Testing of the BRDs in accordance with the ANSI/IEEE N42.53 standard requires verifying the instrument performance at two different radiation background levels. During the development of the BRD TCS document the need to modify or extend this requirement was discussed. Several measurements were performed to evaluate the BRD response to increasing background radiation.

Natural occurring radioactive materials (NORM) can be used to increase the background radiation level during testing. In the ANSI/IEEE standard, testing is carried out in a "low" radiation background condition defined as $10 \mu \mathrm{R} / \mathrm{h} \pm 50 \%(\mathrm{k}=1)$ and in a "high" radiation background condition defined as $30 \mu \mathrm{R} / \mathrm{h} \pm 20 \%(\mathrm{k}=1)$. In order to assess the BRD response to different background conditions a ${ }^{226} \mathrm{Ra}$ and a ${ }^{232} \mathrm{U}$ source were placed inside a $9 \mathrm{~cm}$ thick 
PMMA container to simulate a NORM [5] and increase the radiation background level. The Victoreen 451P-DE-SI-RYR was used to measure the background dose equivalent rate. The background dose equivalent rate was set by placing the ${ }^{226} \mathrm{Ra}$ and ${ }^{232} \mathrm{U}$ sources inside the PMMA at different distances from the BRD, the dose equivalent rates used for the measurements were $0.1 \mu \mathrm{Sv} / \mathrm{h}, 0.2 \mu \mathrm{Sv} / \mathrm{h}, 0.3 \mu \mathrm{Sv} / \mathrm{h}, 0.4 \mu \mathrm{Sv} / \mathrm{h}$ and $0.5 \mu \mathrm{Sv} / \mathrm{h}$.

For each one of these fixed background levels, a ${ }^{57} \mathrm{Co}$ and ${ }^{133} \mathrm{Ba}$ source producing a fluence rate of 0.68 photons $/ \mathrm{s} / \mathrm{cm}^{2}$ and 1.1 photons $/ \mathrm{s} / \mathrm{cm}^{2}$ respectively were moved past the BRD-2 at $1.2 \mathrm{~m} / \mathrm{s}$ and the alarm level as well as the radionuclides identified were recorded. The PMMA phantom was placed behind the BRD-2. The BRD-2 was allowed to reset its background each time the background dose equivalent rate was increased. When the BDR-2 detects a source it produces an alarm, displays the alarm level (a number between 1 and 9) and displays the radionuclides identified. There was a total number of 10 trials per source, see the results for the ${ }^{133} \mathrm{Ba}$ and ${ }^{57} \mathrm{Co}$ sources in Figure 4 through Figure 7. These figures show the alarm levels and radionuclides identified for the 10 trials as a function of the different background dose equivalent rates. From these figures it can be observed that the BRD-2 is not capable of identifying the sources, as there was no radionuclide identified, when the background dose equivalent rate is increased above $0.1 \mu \mathrm{Sv} / \mathrm{h}$. The BRD-2 alarm level is reduced when the background dose equivalent rate is increased. The BRD-2 sensitivity is reduced with increased background dose equivalent rate.

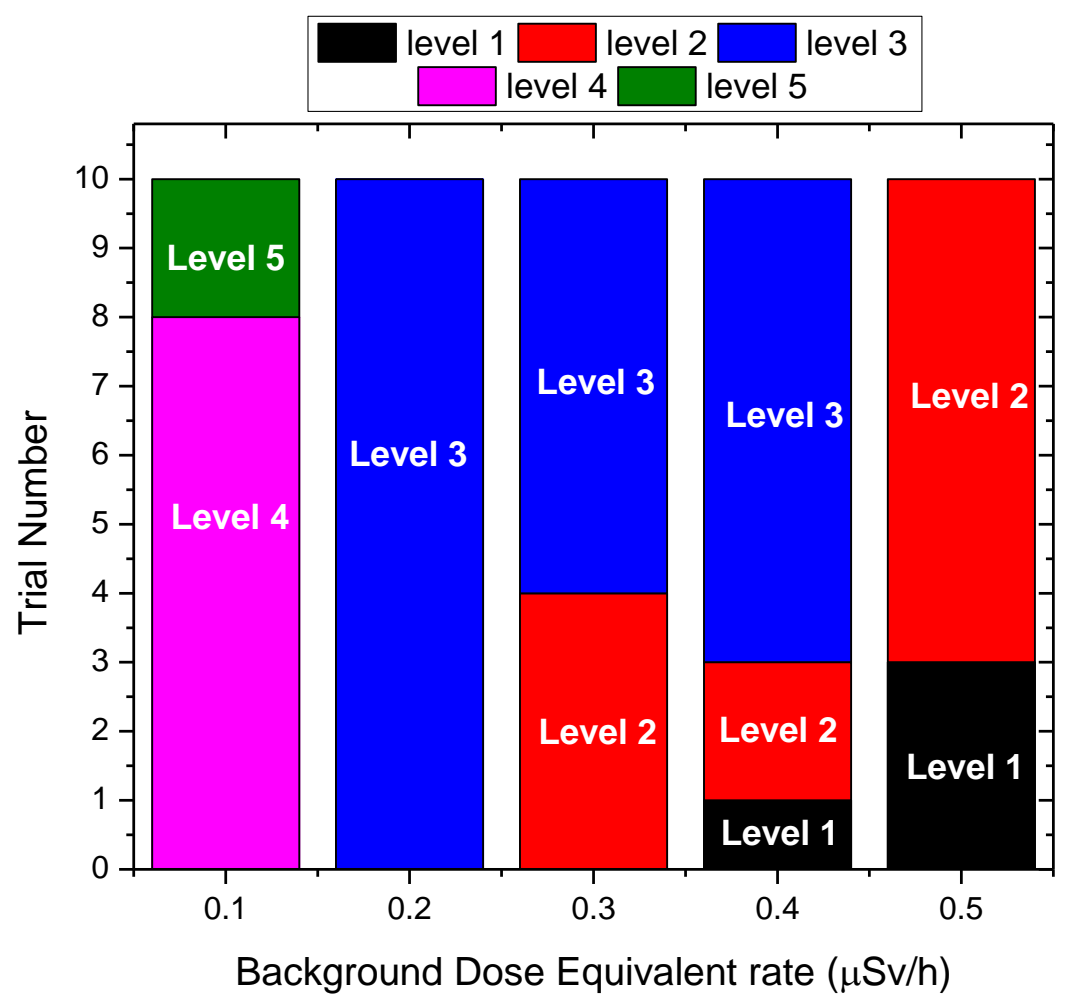

Figure 4: Alarm levels for BRD-2 produced by ${ }^{57} \mathrm{Co}$ source for different background radiation levels 


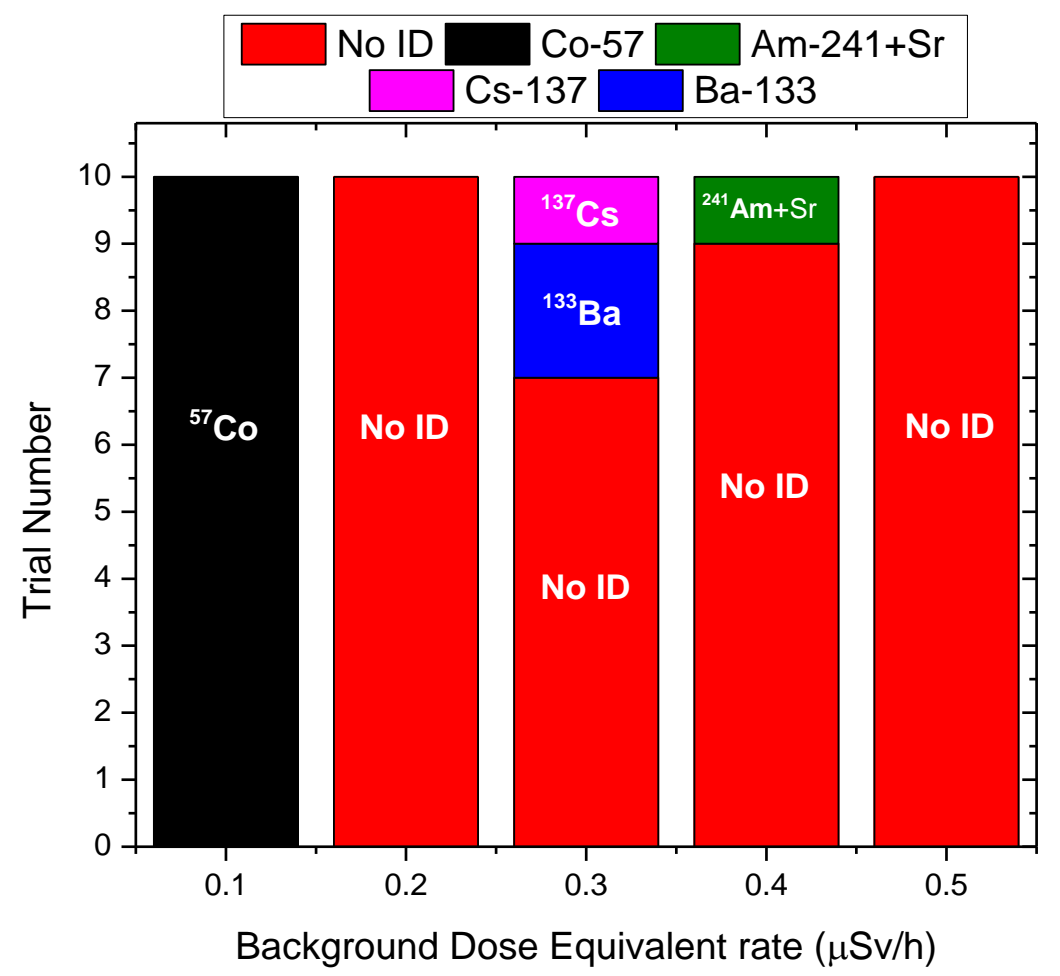

Figure 5: Radionuclide identification for BRD-2 produced by ${ }^{57} \mathrm{Co}$ source for different background radiation levels

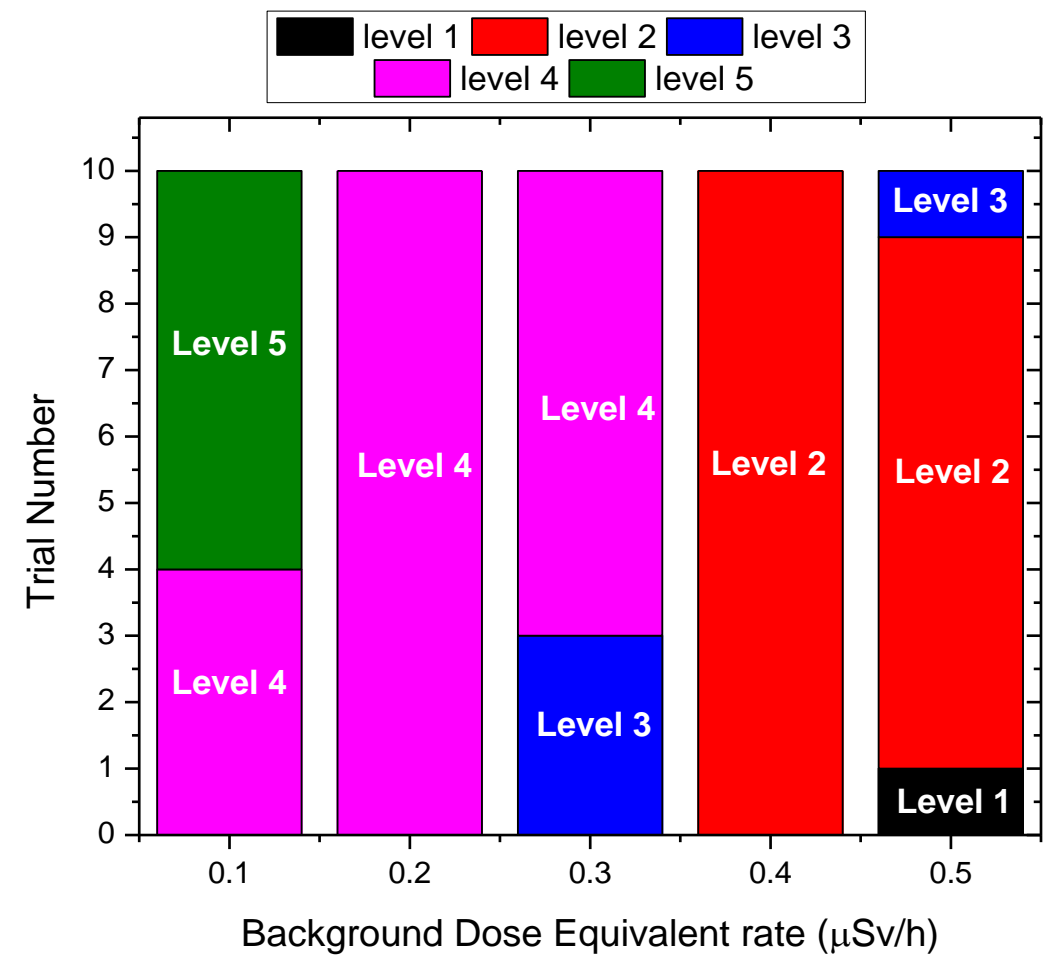

Figure 6: Alarm levels for BRD-2 produced by ${ }^{133}$ Ba source for different background radiation levels 


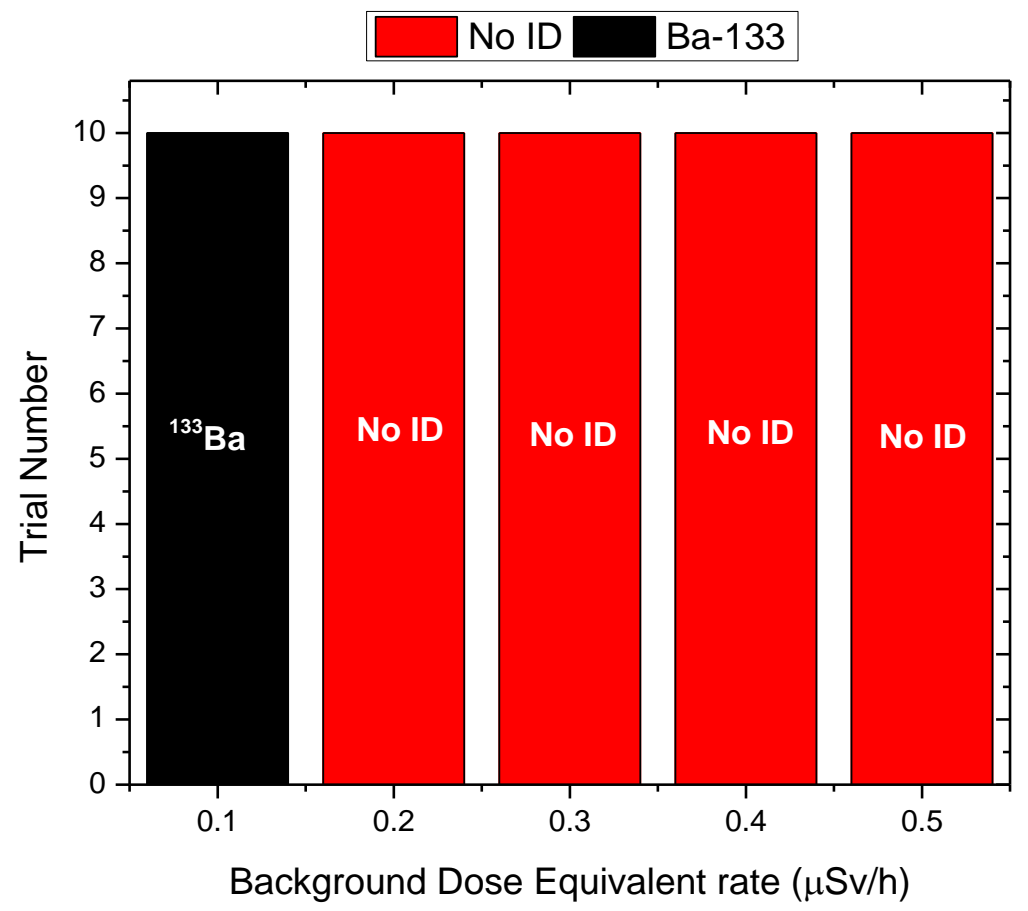

Figure 7: Radionuclide identification for BRD-2 produced by ${ }^{133}$ Ba source for different background radiation levels

\subsection{Suitability of fluence rate values used for testing BRDs}

Currently, there are several requirements for different types of radiation detection systems including BRDs. The ANSI N42.53 [1] standard requires testing the BRDs alarm response function using a field of 4 photons $/ \mathrm{s} / \mathrm{cm}^{2}\left( \pm 5 \%, 1\right.$-standard deviation) for ${ }^{241} \mathrm{Am},{ }^{57} \mathrm{Co},{ }^{137} \mathrm{Cs}$ and ${ }^{60} \mathrm{Co}$. It also requires the identification of several radionuclides (i.e., ${ }^{57} \mathrm{Co},{ }^{60} \mathrm{Co},{ }^{67} \mathrm{Ga},{ }^{99 \mathrm{~m}} \mathrm{Tc},{ }^{131} \mathrm{I}$, ${ }^{133} \mathrm{Ba},{ }^{137} \mathrm{Cs},{ }^{201} \mathrm{Tl},{ }^{226} \mathrm{Ra},{ }^{232} \mathrm{Th},{ }^{241} \mathrm{Am}, \mathrm{HEU}, \mathrm{DU}$, and WGPu) producing an exposure rate of 5 $\mu \mathrm{R} / \mathrm{h}$ ( $\pm 20 \%, 1$-standard deviation) above background at the reference point of the BRD. The DNDO Radioisotope Identification Devices (RIIDs) TCS document [3], specifies that these instruments shall identify the bare and shielded sources listed in Table 4 through Table 6 depending on the category of use, (e.g., Conveyances/ Pedestrians, Containerized Cargo). In turn, the DNDO Traceability Memo [2] requires different source quantities to be used for testing of radiation detection systems used for homeland security applications. Based on the DNDO Traceability Memo [2] and the results of the measurements presented in this work, the draft version of the BRD TCS proposes the use of the sources listed in Table 6 and Table 7.

Table 4: HEU, WGPU and DU Shielded and Bare Sources - RIIDs Conveyances/Pedestrians Category

\begin{tabular}{|l|c|c|c|}
\hline Source & Shielding material & $\begin{array}{c}\text { Minimum source } \\
\text { thickness }(\mathbf{m m}) * *\end{array}$ & $\begin{array}{c}\text { Fluence rate at } \\
\text { reference point } \\
(\text { photons/s/cm } \mathbf{2}) * \dagger\end{array}$ \\
\hline HEU & None & 1 & $0.68 \pm 10 \%$ \\
\hline
\end{tabular}




\begin{tabular}{|c|c|c|c|}
\hline Source & Shielding material & $\begin{array}{l}\text { Minimum source } \\
\text { thickness }(\mathrm{mm}) * *\end{array}$ & $\begin{array}{l}\text { Fluence rate at } \\
\text { reference point } \\
\left(\text { photons } / \mathrm{s} / \mathrm{cm}^{2}\right) * \dagger\end{array}$ \\
\hline $\mathrm{HEU}$ & Steel & 1 & $0.68 \pm 10 \%$ \\
\hline $\mathrm{HEU}$ & HDPE & 1 & $0.68 \pm 10 \%$ \\
\hline WGPu & None & 5 & $1.1 \pm 10 \%$ \\
\hline WGPu & Steel & 5 & $1.1 \pm 10 \%$ \\
\hline $\mathrm{WGPu}$ & HDPE & 5 & $1.1 \pm 10 \%$ \\
\hline $\mathrm{DU}$ & None & 3 & $0.22 \pm 10 \%$ \\
\hline $\mathrm{DU}$ & Steel & 3 & $0.22 \pm 10 \%$ \\
\hline $\mathrm{DU}$ & HDPE & 3 & $0.22 \pm 10 \%$ \\
\hline \multicolumn{4}{|c|}{$\begin{array}{l}\text { * Uncertainties have a coverage factor, } \mathrm{k} \text {, of } 1 \text {. } \\
* * \text { Thickness are based in the } 95 \% \text { of infinite thickness emission rate, see Reference } 15 \text {. The DU thickness } \\
\text { is based on commonly available standard reference materials. } \\
\dagger \text { Fluence rates correspond to a radiation background level of } 20 \mu \mathrm{R} / \mathrm{h}\end{array}$} \\
\hline
\end{tabular}

Table 5: DU, HEU and WGPU Shielded and Bare Sources - RIIDs Containerized Cargo Category

\begin{tabular}{|c|c|c|c|}
\hline Source & Shielding material & $\begin{array}{l}\text { Minimum source } \\
\text { thickness }(\mathrm{mm}) * *\end{array}$ & $\begin{array}{c}\text { Fluence rate at } \\
\text { testing point } \\
\left(\text { photons } / \mathrm{s} / \mathrm{cm}^{2}\right) *+\end{array}$ \\
\hline $\mathrm{HEU}$ & None & 1 & $1.6 \pm 10 \%$ \\
\hline $\mathrm{HEU}$ & None & 1 & $0.18 \pm 10 \%$ \\
\hline $\mathrm{HEU}$ & Steel & 1 & $0.18 \pm 10 \%$ \\
\hline $\mathrm{HEU}$ & HDPE & 1 & $0.18 \pm 10 \%$ \\
\hline WGPu & None & 5 & $3.8 \pm 10 \%$ \\
\hline $\mathrm{WGPu}$ & None & 5 & $0.30 \pm 10 \%$ \\
\hline $\mathrm{WGPu}$ & Steel & 5 & $0.30 \pm 10 \%$ \\
\hline $\mathrm{WGPu}$ & HDPE & 5 & $0.30 \pm 10 \%$ \\
\hline
\end{tabular}

Table 6: ${ }^{237} \mathrm{~Np}$ Test Cases - All Instrument Categories

\begin{tabular}{|l|c|c|c|c|c|c|}
\hline $\begin{array}{c}\text { Target } \\
\text { Source }\end{array}$ & Quantity & Distance $(\mathbf{m})$ & $\begin{array}{c}\text { Shielding } \\
\text { material }\end{array}$ & $\begin{array}{c}\text { Shielding } \\
\text { thickness }\end{array}$ & $\begin{array}{c}\text { Masking } \\
\text { source }\end{array}$ & $\begin{array}{c}\text { Masking } \\
\text { ratio }\end{array}$ \\
\hline${ }^{237} \mathrm{~Np}$ & $90 \mathrm{mg} *$ & 1.5 & None & None & None & None \\
\hline$*$ shielded by $1 \mathrm{~cm}$ of steel
\end{tabular}


Table 7: BRD HEU, WGPu and DU shielded and bare sources

\begin{tabular}{|c|c|c|c|c|}
\hline Source & Shielding material & $\begin{array}{l}\text { Minimum } \\
\text { source } \\
\text { thickness } \\
(\mathrm{mm}) * *\end{array}$ & $\begin{array}{c}\text { Fluence rate of the } \\
\text { source at reference } \\
\text { point } \\
\text { (photons/s/cm2)* }\end{array}$ & $\begin{array}{l}\text { Shielding thickness } \\
(\mathrm{cm}) \dagger\end{array}$ \\
\hline HEU & None & 1 & $0.94 \pm 10 \%$ & NA \\
\hline HEU & Lead & 1 & $0.94 \pm 10 \%$ & 0.05 \\
\hline $\mathrm{HEU}$ & Steel & 1 & $0.94 \pm 10 \%$ & 0.53 \\
\hline $\mathrm{HEU}$ & HDPE & 1 & $0.94 \pm 10 \%$ & 5.37 \\
\hline HEU & Steel + HDPE & 1 & $0.94 \pm 10 \%$ & $0.26 \mathrm{Steel} / 2.68 \mathrm{HDPE}$ \\
\hline WGPu & None & 5 & $2.30 \pm 10 \%$ & NA \\
\hline WGPu & Lead & 5 & $2.30 \pm 10 \%$ & 0.27 \\
\hline WGPu & Steel & 5 & $2.30 \pm 10 \%$ & 1.00 \\
\hline WGPu & HDPE & 5 & $2.30 \pm 10 \%$ & 7.18 \\
\hline WGPu & Steel + HDPE & 5 & $2.30 \pm 10 \%$ & 0.5 Steel/3.59 HDPE \\
\hline DU & None & 3 & $0.34 \pm 10 \%$ & NA \\
\hline
\end{tabular}

Several tests and calculations were performed to investigate the suitability and differences in requirements proposed for testing of the BRDs.

Calculations were performed to determine the fluence rate and activities of several sources when placed at a distance of $2 \mathrm{~m}$ from the BRD producing an exposure rate $5 \mu \mathrm{R} / \mathrm{h}$ and $50 \mu \mathrm{R} / \mathrm{h}$ above background at the reference point of the BRD, results of these calculations are shown in Table 8 . These calculations assume the emission coming from a point source [7], uses a cut-off energy of $40 \mathrm{keV}$ and includes all gamma-rays with their emission probability.

Table 8: Fluence rate and activities for several sources when placed at a distance of $2 \mathrm{~m}$ producing an exposure rate $5 \mu \mathrm{R} / \mathrm{h}$ and $50 \mu \mathrm{R} / \mathrm{h}$ above background at the reference point of the BRD

\begin{tabular}{|c|c|c|c|c|}
\hline Source & $\begin{array}{c}\text { Activity (MBq) } \\
\text { for } 5 \mu R \text { field }\end{array}$ & $\begin{array}{l}\text { Fluence rate at } \\
\text { reference point } \\
\left(\text { photons } / \mathrm{s} / \mathrm{cm}^{2}\right)\end{array}$ & $\begin{array}{l}\text { Activity }(\mathrm{MBq}) \\
\text { for } 50 \mu \mathrm{R} \text { field }\end{array}$ & $\begin{array}{l}\text { Fluence rate at } \\
\text { reference point } \\
\left(\text { photons } / \mathrm{s} / \mathrm{cm}^{2}\right)\end{array}$ \\
\hline${ }^{241} \mathrm{Am}$ & 60.1 & 42.9 & 600.7 & 429 \\
\hline${ }^{57} \mathrm{Co}$ & 15.4 & 29.6 & 154.4 & 296 \\
\hline${ }^{237} \mathrm{~Np}$ & 7.83 & 11.6 & 78.30 & 116 \\
\hline${ }^{133} \mathrm{Ba}$ & 3.90 & 10.6 & 38.97 & 106 \\
\hline${ }^{137} \mathrm{Cs}$ & 2.13 & 3.6 & 21.27 & 36 \\
\hline${ }^{60} \mathrm{Co}$ & 0.578 & 2.3 & 5.78 & 23 \\
\hline
\end{tabular}

The exposure rate values used for testing the radionuclide identification capabilities of the BRDs in the ANSI N42.53 standard are orders of magnitude larger than those specified in the TCSs.

Measurements were performed using different source activities listed in Table 9. The source activity is given at the time of the measurements, the uncertainty in the source activity is $\pm 10 \%$ $(\mathrm{k}=1)$. The measured dose rate at $2 \mathrm{~m}$ from the source as well as the calculated exposure rate 
(using the point source approximation described in reference [7]) and fluence rate at $2 \mathrm{~m}$ (for a cut-off energy of $40 \mathrm{keV}$ ), are listed in Table 9. These source activities were selected because they are used for testing BRDs in the ANSI N42.43 standard [4] and they provide a wide range of gamma-ray fields.

Table 9: List of sources used for BRD testing

\begin{tabular}{|c|c|c|c|c|c|c|c|}
\hline Source & $\begin{array}{c}\text { Average } \\
\text { Energy } \\
(\mathbf{k e V})\end{array}$ & $\begin{array}{l}\text { Source } \\
\text { activity } \\
(\mu \mathrm{Ci})^{3}\end{array}$ & $\begin{array}{c}\text { Source } \\
\text { activity }(\mathrm{Bq})\end{array}$ & $\begin{array}{l}\text { Measured Dose } \\
\text { equivalent rate } \\
\text { with Victoreen } \\
(\mu \mathrm{Sv} / \mathrm{h}) \text { at } 2 \mathrm{~m} \\
\end{array}$ & Unc (\%) & $\begin{array}{c}\text { Calculated } \\
\text { exposure rate } \\
(\boldsymbol{\mu R} / \mathbf{h}) / \mathbf{1 0 0} \text { at } \mathbf{2 \mathbf { m } ^ { \dagger }}\end{array}$ & \begin{tabular}{|c}
$\begin{array}{c}\text { Calculated } \\
\text { fluence rate } \\
\left(\text { photons } / \mathrm{cm}^{2} / \mathrm{s}\right) \\
\text { at } 2 \mathrm{~m}\end{array}$ \\
\end{tabular} \\
\hline${ }^{241} \mathrm{Am}$ & 59.5 & 51.05 & $1.89 \mathrm{E}+06$ & 0 & 31.86 & 0.0016 & 1.35 \\
\hline${ }^{57} \mathrm{Co}$ & 124.5 & 18.21 & $6.74 \mathrm{E}+05$ & 0.0010 & 42.61 & 0.0022 & 1.29 \\
\hline${ }^{237} \mathrm{~Np}$ & 251.7 & 68.65 & $2.54 \mathrm{E}+06$ & 0.0283 & 37.03 & 0.0162 & 3.76 \\
\hline${ }^{133} \mathrm{Ba}$ & 266.4 & 13.74 & $5.08 \mathrm{E}+05$ & 0.0120 & 22.09 & 0.0065 & 1.38 \\
\hline${ }^{137} \mathrm{Cs}$ & 661.7 & 13.62 & $5.04 \mathrm{E}+05$ & 0.0133 & 43.74 & 0.0118 & 0.85 \\
\hline${ }^{60} \mathrm{Co}$ & 1252.8 & 39.89 & $1.48 \mathrm{E}+06$ & 0.1160 & 17.18 & 0.1276 & 5.87 \\
\hline
\end{tabular}

The sources listed in Table 9 were used to determine the total count rate peak efficiency per Becquerel (Bq) at a distance of $2 \mathrm{~m}$ for BRD-1 and BRD-2. The results of these measurements are shown in Figure 8 and Figure 9, in these figures the $\mathrm{x}$-axis represents the average energy for each source. The measured efficiency for BRD-2 is larger than that of BRD-1.

\footnotetext{
${ }^{3}$ NIST does not endorse the use of non-SI units. This paper uses non-SI units because it addresses the requirements listed in the ANSI/IEEE published standards.
} 


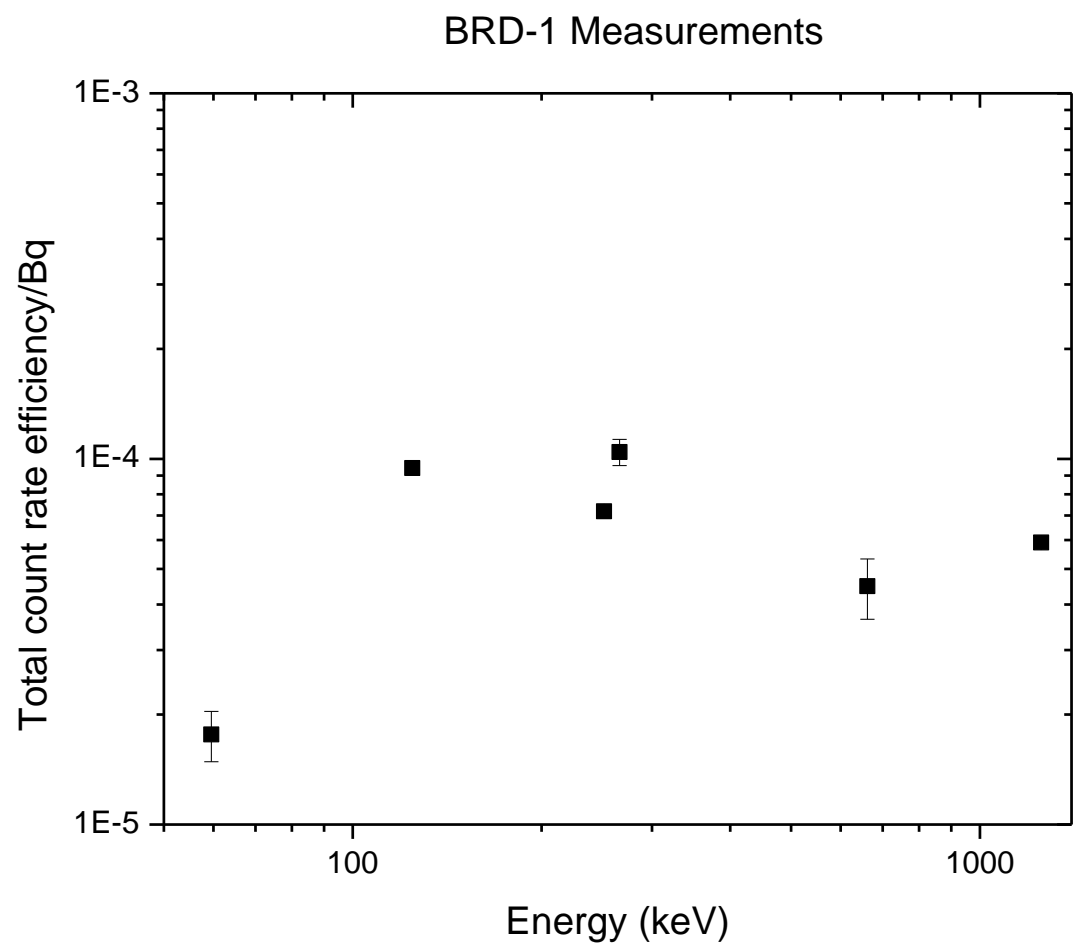

Figure 8: Total count rate efficiency per Bq for BRD-1 at 2 m; uncertainties are 1-standard deviation.

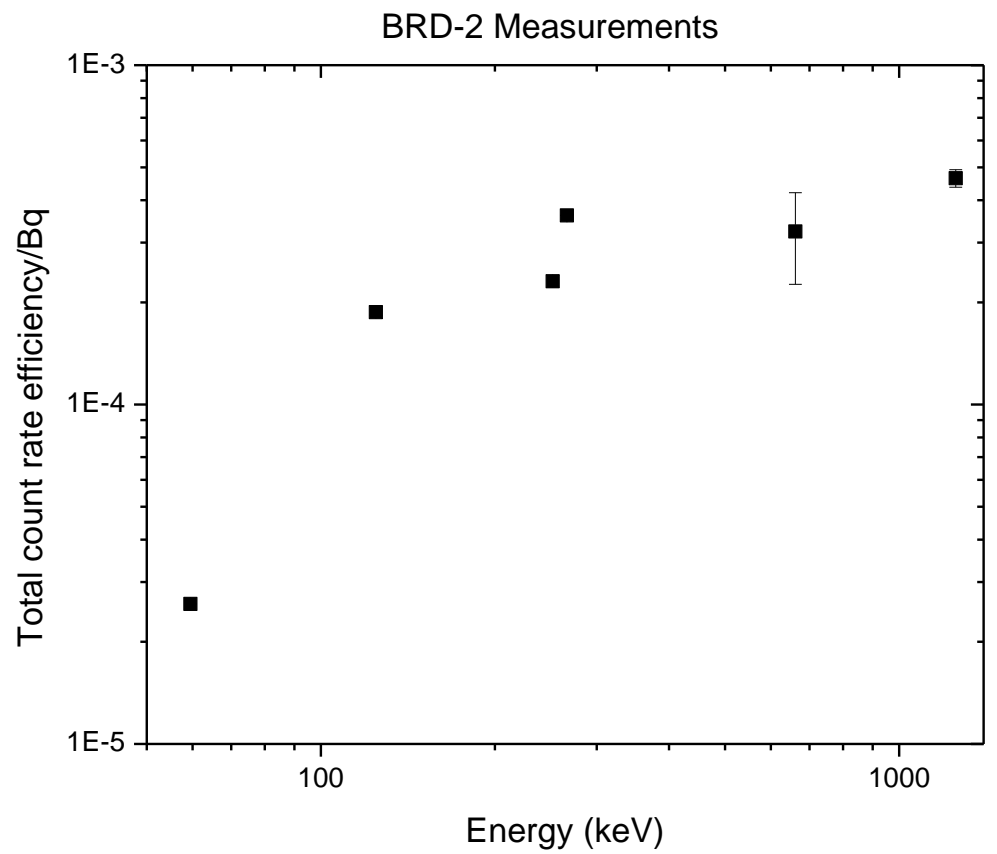

Figure 9: Total count rate efficiency per Bq for BRD-2 at 2 m; uncertainties are 1-standard deviation. 
The sources were moved passed the BRD-1 and BRD-2 at a speed of $1.2 \mathrm{~m} / \mathrm{s}$ and $2.2 \mathrm{~m} / \mathrm{s}$ with and without the presence of the PMMA phantom for total of 10 trials for each source, with a distance of closest approach of $2 \mathrm{~m}$. The BRD-1 and BRD- 2 can display a count rate or a level when detecting a radioactive source besides the alarm. For the BRD-1 the results are given based on the alarm and radiation level indication, see Figure 10 through Figure 12. From these figures it can be observed that the BRD-1 did not alarm to the ${ }^{137} \mathrm{Cs}$ producing a fluence rate of 0.85 photons $/ \mathrm{s} / \mathrm{cm}^{2}$ at the reference point of the BRD. The presence of the PMMA phantom seems to increase the radiation level response for all sources. For the ${ }^{241} \mathrm{Am}$ source the BRD-1 response is lower than that of the ${ }^{133} \mathrm{Ba}$ even when both sources produce a similar fluence rate, this can be explained by the drop in counting efficiency for the $60 \mathrm{keV}$ gamma-ray emitted by ${ }^{241} \mathrm{Am}$.

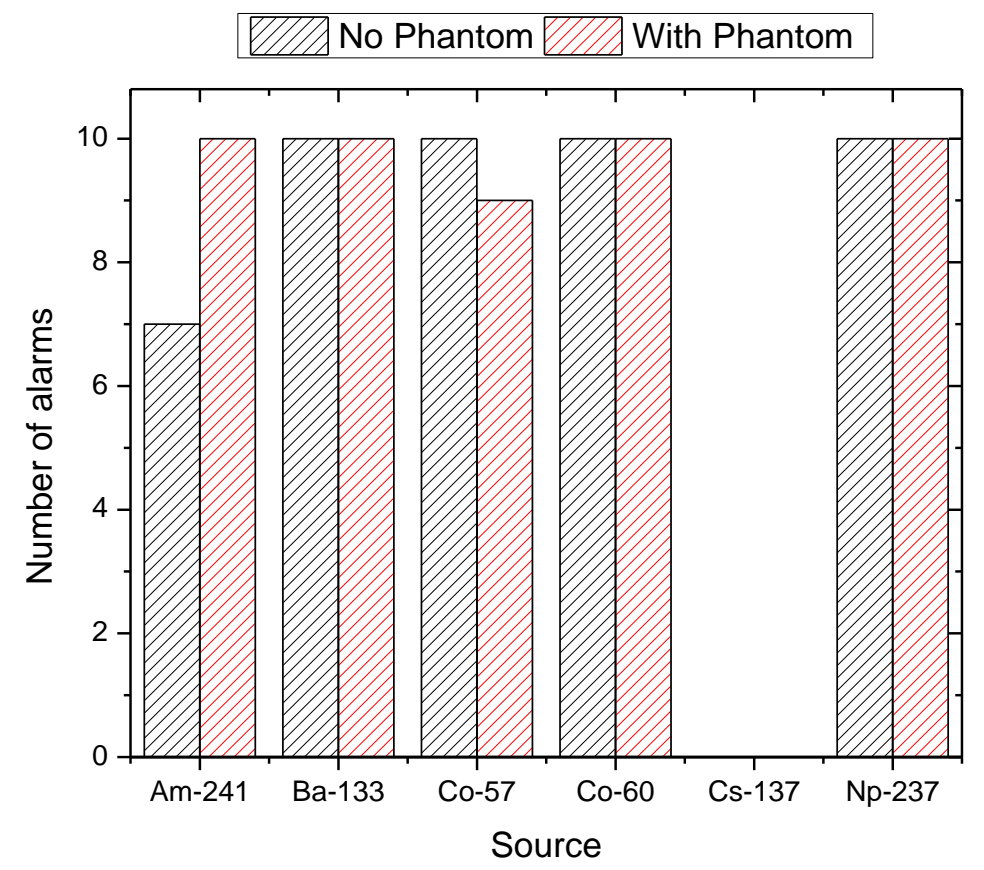

Figure 10: BRD-1 alarm indication with and without PMMA phantom, source speed $1.2 \mathrm{~m} / \mathrm{s}$, distance $2 \mathrm{~m}$ 


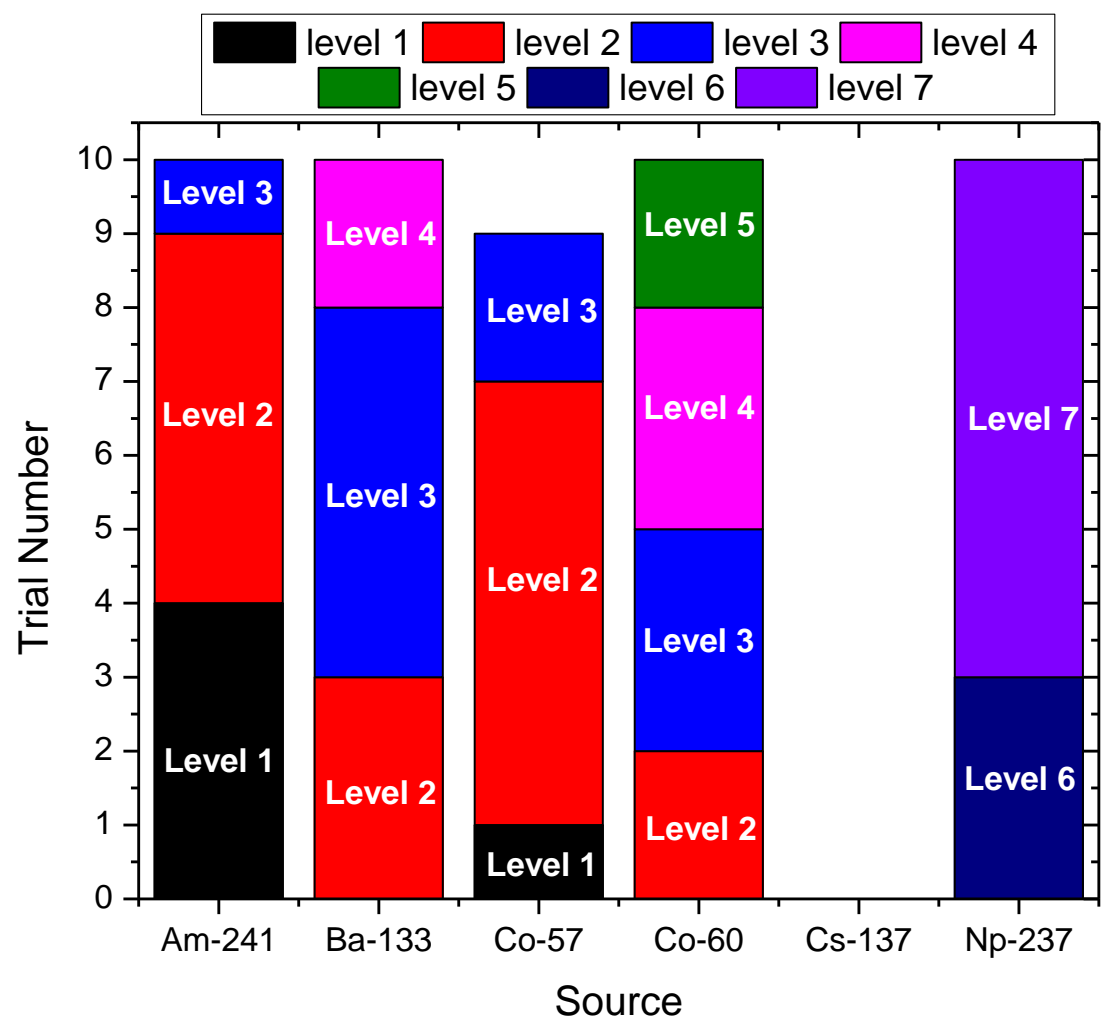

Figure 11: BRD-1 level indication with PMMA phantom, source speed $1.2 \mathrm{~m} / \mathrm{s}$, distance $2 \mathrm{~m}$ 


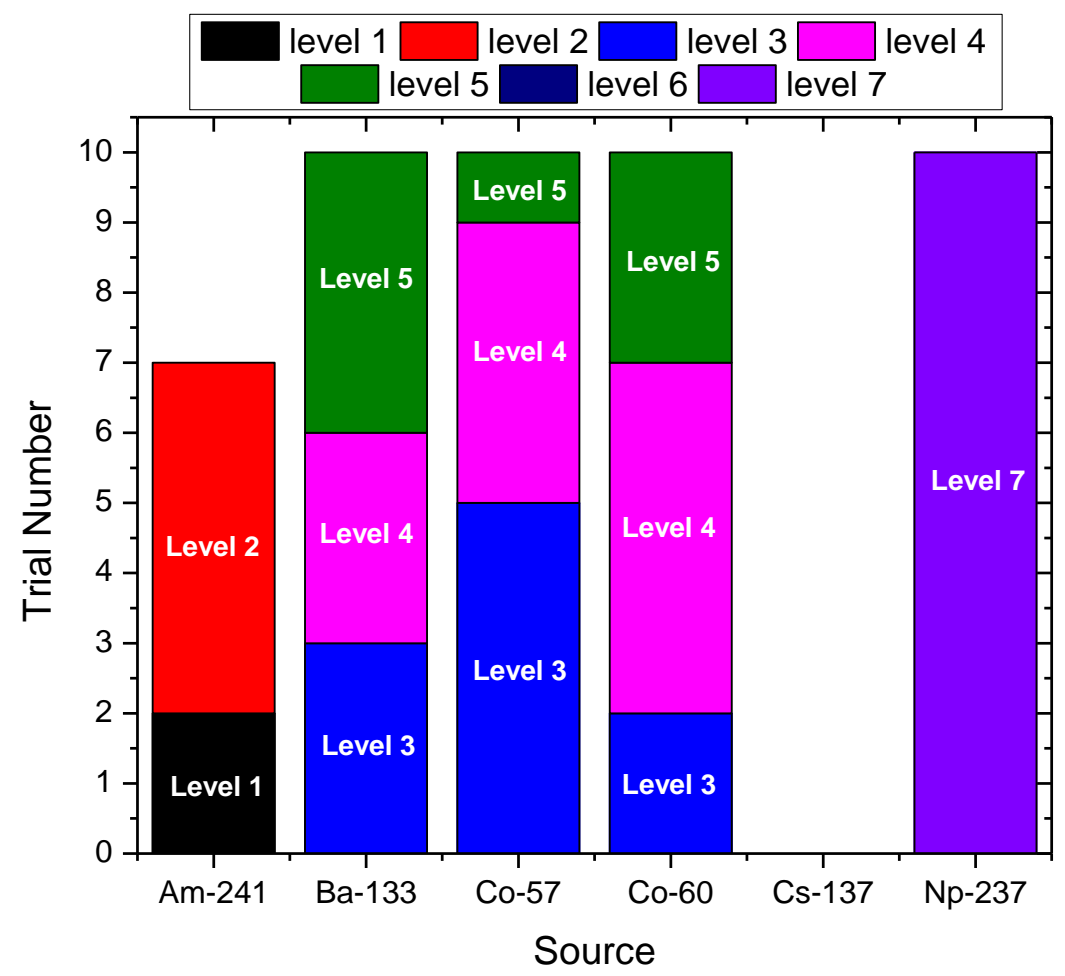

Figure 12: BRD-1 level indication without PMMA phantom, source speed $1.2 \mathrm{~m} / \mathrm{s}$, distance $2 \mathrm{~m}$

For the BRD-2 the results are given based on alarm, radiation level indication and the radionuclide identification information, see Figure 13 through Figure 17. The BRD-2 has no problems detecting any of the sources but it seems to have some difficulties identifying ${ }^{60} \mathrm{Co}$. There seems to be small difference in response with the presence of the PMMA phantom. For some sources the BRD-2 was not able to correctly identify the radionuclide present 10 out of 10 times. 


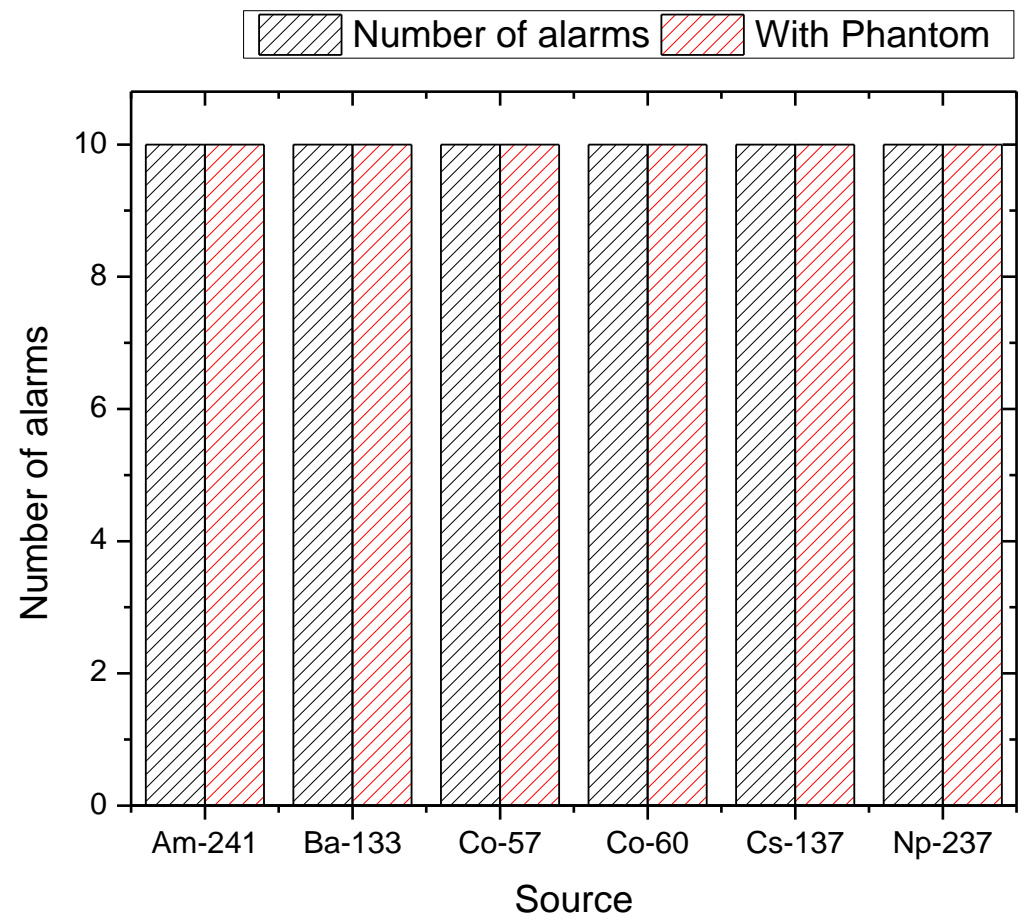

Figure 13: BRD-2 alarm indication with and without PMMA phantom, source speed $1.2 \mathrm{~m} / \mathrm{s}$, distance $2 \mathrm{~m}$

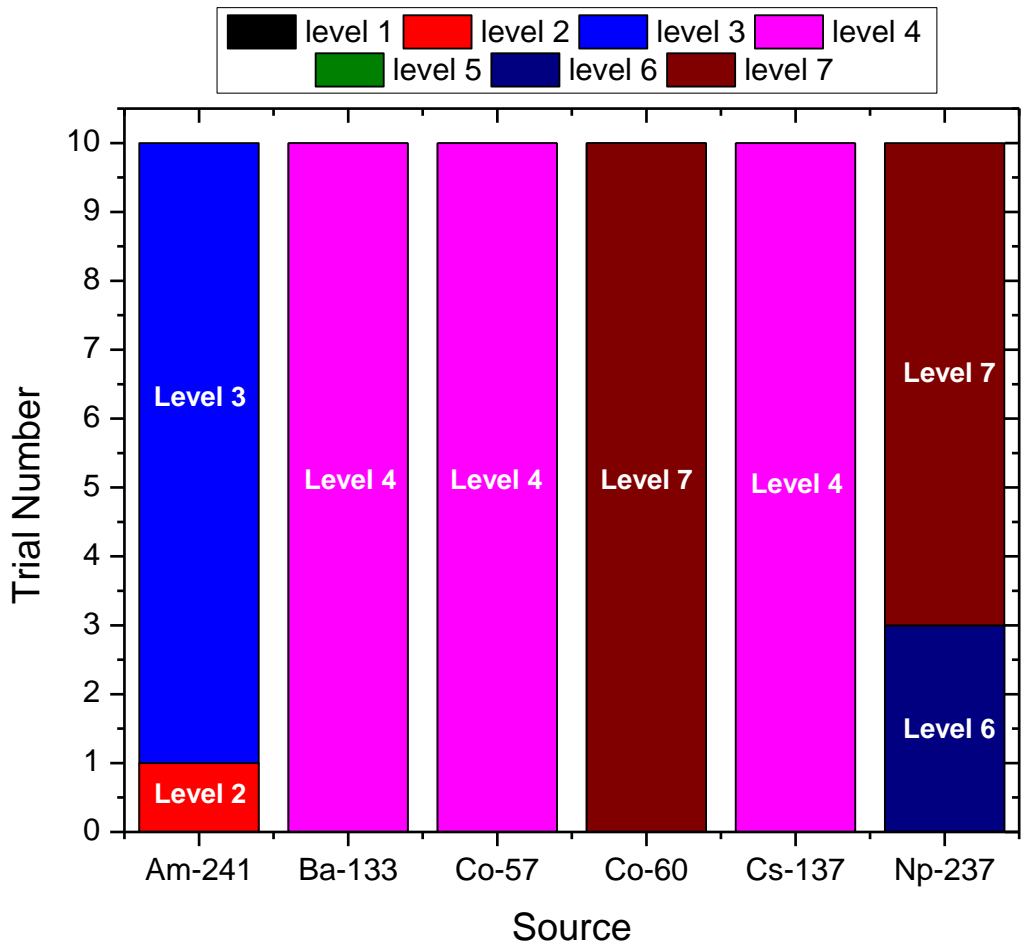

Figure 14: BRD-2 level indication with PMMA phantom, source speed $1.2 \mathrm{~m} / \mathrm{s}$, distance $2 \mathrm{~m}$ 


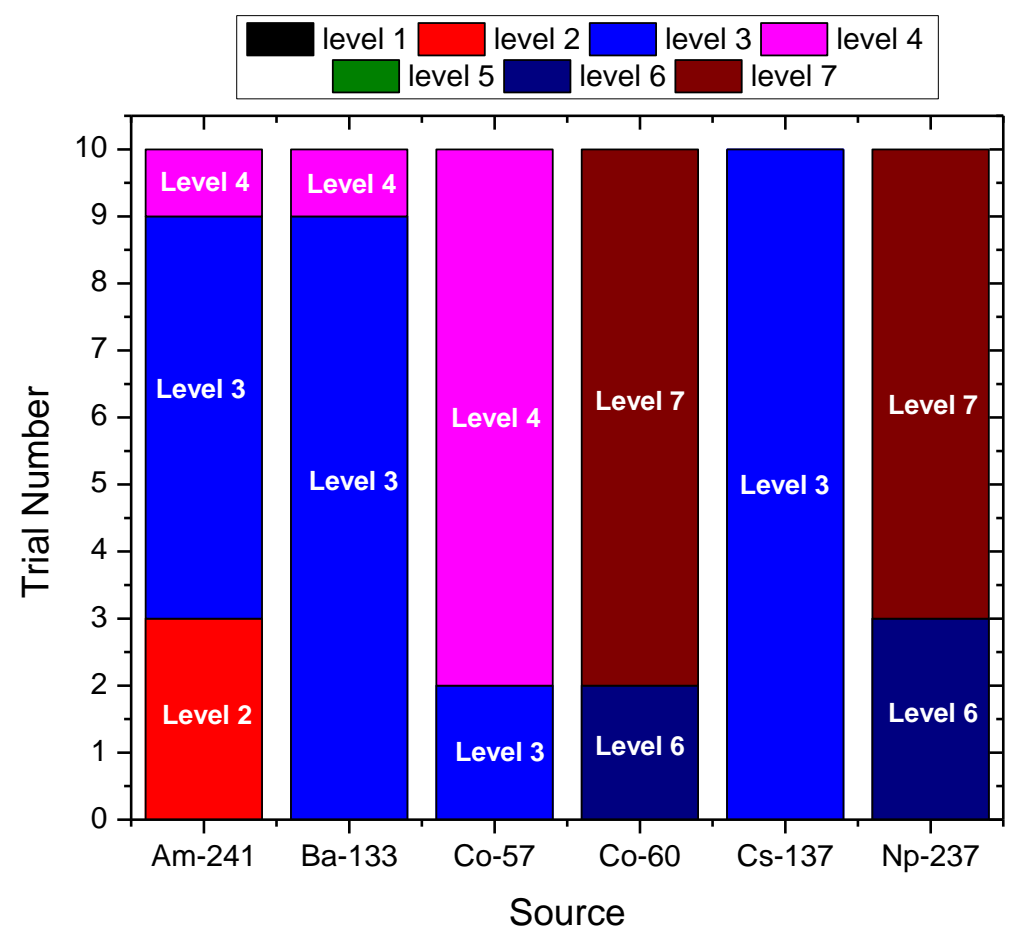

Figure 15: BRD-2 level indication without PMMA phantom, source speed $1.2 \mathrm{~m} / \mathrm{s}$, distance $2 \mathrm{~m}$

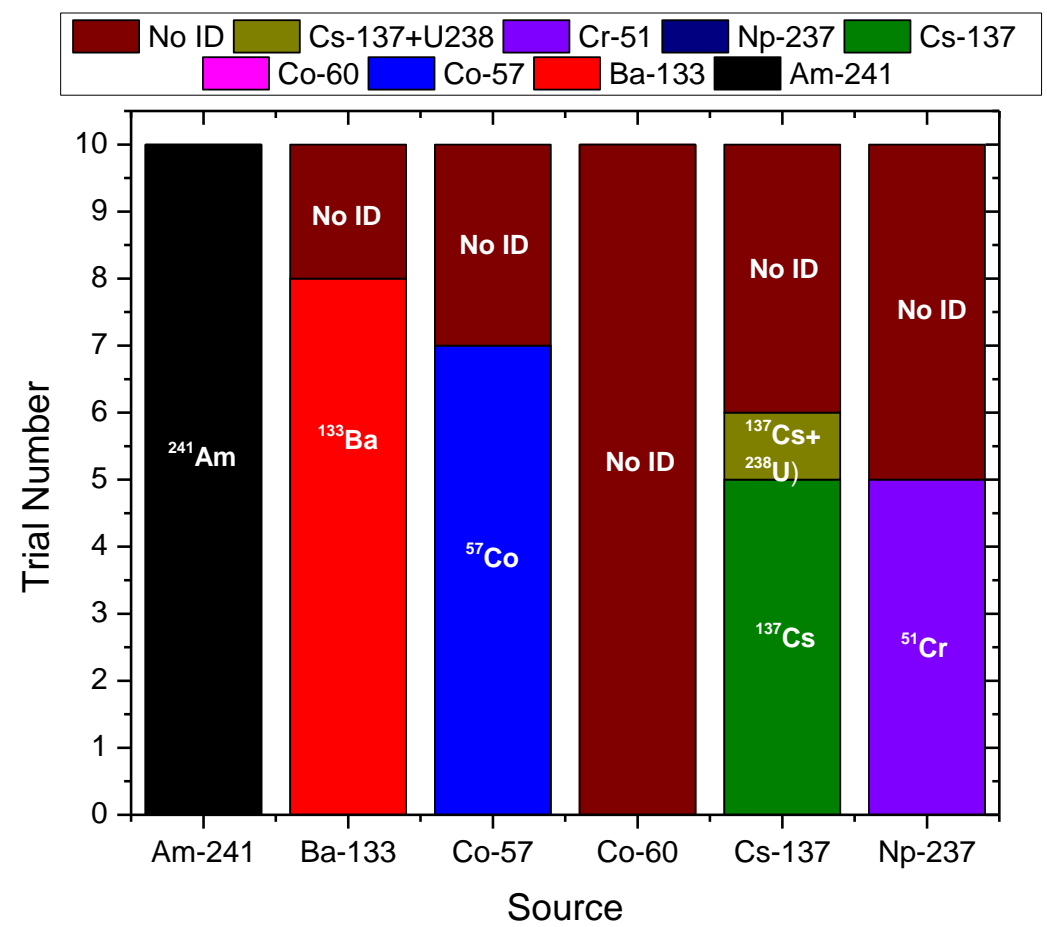

Figure 16: BRD-2 radionuclide identification indication with PMMA phantom, source speed $1.2 \mathrm{~m} / \mathrm{s}$, distance $2 \mathrm{~m}$ 


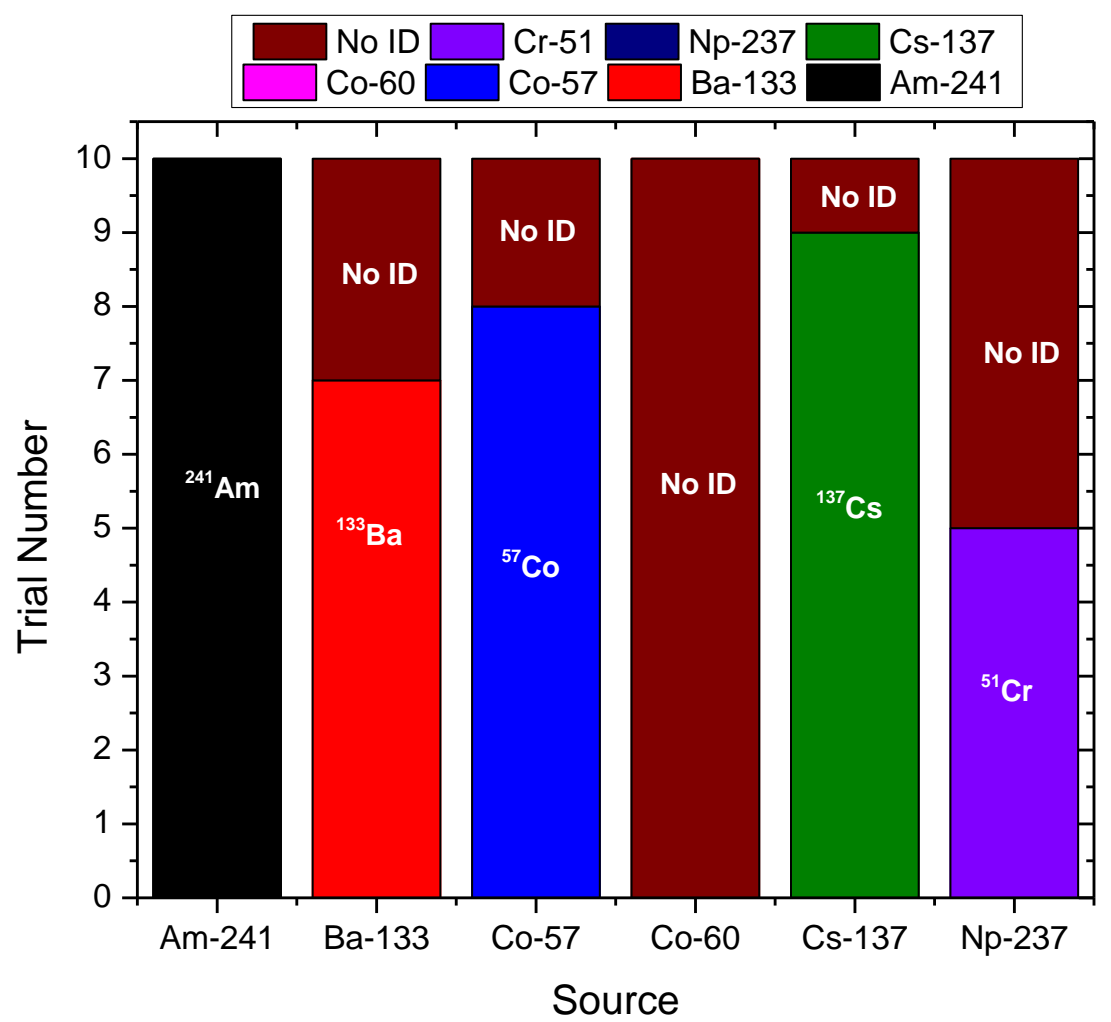

Figure 17: BRD-2 radionuclide identification indication without PMMA phantom, source speed $1.2 \mathrm{~m} / \mathrm{s}$, distance $2 \mathrm{~m}$

For the ${ }^{237} \mathrm{~Np}$ source several additional measurements were performed to evaluate the BRD response based on the differences in source specifications in the ANSI/IEEE standard and TCS. The ANSI/IEEE N42.43 standard requires testing with a $90 \mathrm{mg}{ }^{237} \mathrm{~Np}$ shielded by $1 \mathrm{~cm}$ of steel. During the development of the TCS it was suggested the use of a $90 \mathrm{mg}{ }^{237} \mathrm{~Np}$ without the steel shielding. Therefore, measurements were performed with and without the steel shielding. Figure 18 shows the BRD-2 radiation level indication results without the presence of the phantom with the source placed at $2 \mathrm{~m}$ from the BRD-2, with and without the steel shielding. The radionuclide identification of ${ }^{237} \mathrm{~Np}$ was not changed by the use of the shielding. The BRD-2 net gamma-ray count rates for the static measurements were reduced from $570 \pm 13 \mathrm{cps}$ to $292 \pm 9 \mathrm{cps}$ from the bare to the shielded source configuration at a distance of $2 \mathrm{~m}$ and from $286 \pm 12 \mathrm{cps}$ to $144 \pm 10 \mathrm{cps}$ when the source was placed at a distance of $3 \mathrm{~m}$. All uncertainties have a coverage factor, $k$, of 1 . 


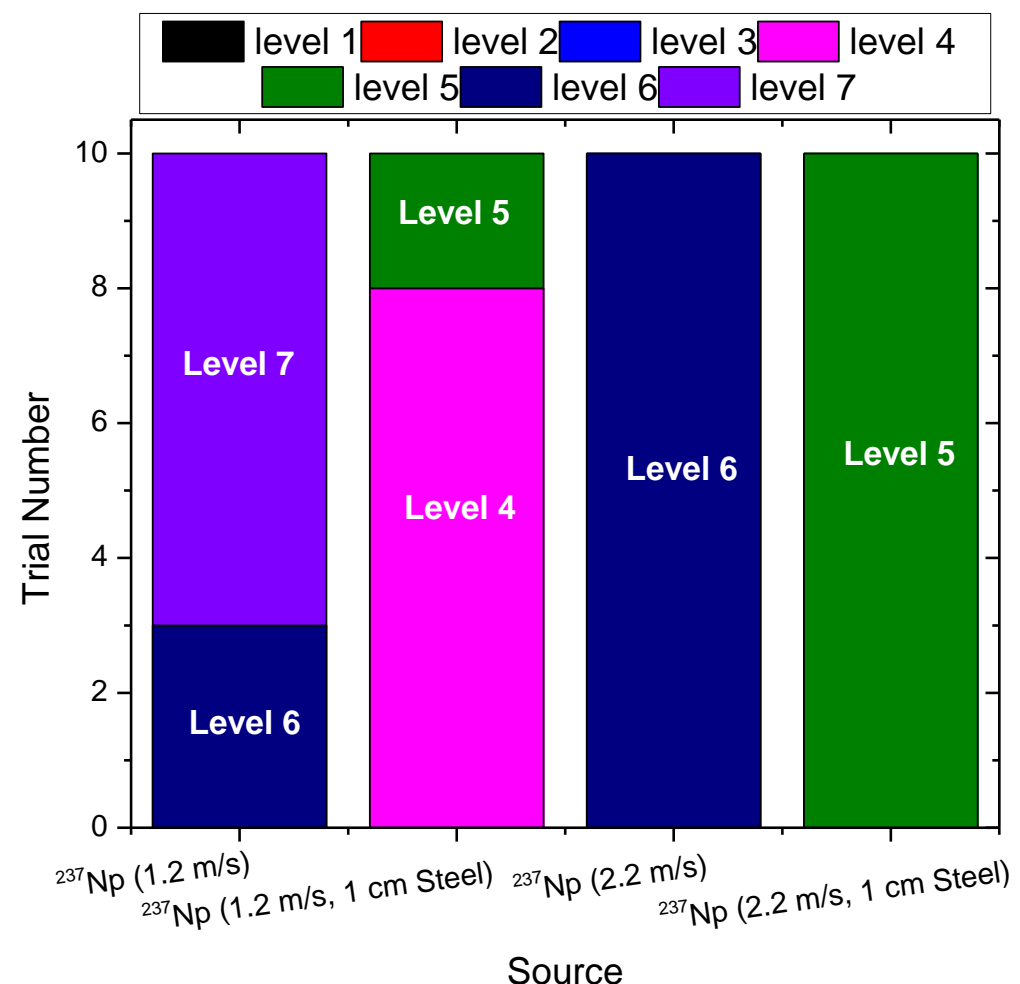

Figure 18: BRD-2 level indication of ${ }^{237} \mathrm{~Np}$ without PMMA phantom, source speed $1.2 \mathrm{~m} / \mathrm{s}$ and $2.2 \mathrm{~m} / \mathrm{s}$, distance $2 \mathrm{~m}$

Similar ${ }^{237} \mathrm{~Np}$ source measurements were performed using the BRD-1 and the BRD-3 without a phantom. The BRD-1 net gamma-ray count rates for the static measurements were reduced from $90 \pm 20 \mathrm{cps}$ to $42 \pm 22 \mathrm{cps}$ from the bare to the shielded source configuration at a distance of $3 \mathrm{~m}$. For the shielded configuration the gamma-ray count rate for the static measurements at $2 \mathrm{~m}$ was $67 \pm 23 \mathrm{cps}$. All uncertainties have a coverage factor, $k$, of 1 . The results of the dynamic measurements using the shielded ${ }^{237} \mathrm{~Np}$ source at $2 \mathrm{~m}$ are shown in Figure 19. 


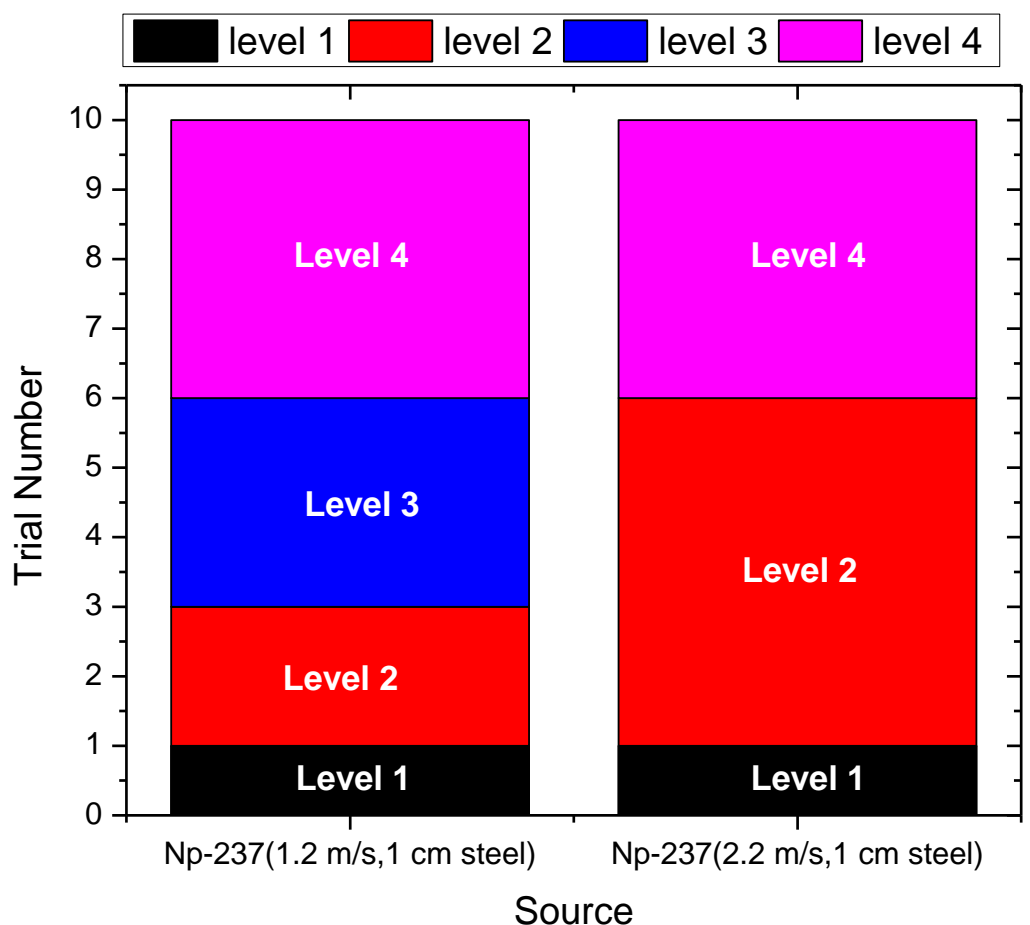

Figure 19: BRD-1 level indication of ${ }^{237} \mathrm{~Np}$ without PMMA phantom, source speed $1.2 \mathrm{~m} / \mathrm{s}$ and $2.2 \mathrm{~m} / \mathrm{s}$, distance $2 \mathrm{~m}$

The BRD-3 did not respond to the shielded ${ }^{237} \mathrm{~Np}$ source at a distance of $2 \mathrm{~m}$ at a speed of $1.2 \mathrm{~m} / \mathrm{s}$. For the static measurements the gamma-ray reading level was equal to 1 .

From these measurements it can be observed that the source activities specified in Table 9 are detectable for most BRDs at a distance of $2 \mathrm{~m}$. The $90 \mathrm{mg}{ }^{237} \mathrm{~Np}$ shielded by $1 \mathrm{~cm}$ of steel seems to be a strong source for testing the BRDs with the source placed or moving pass the BRD at a distance of $2 \mathrm{~m}$.

\subsection{Calculations of emission rates and/or fluence rate for SNM and DU sources}

A depleted uranium (DU) source was measured using three different HPGe detectors. Two of the detectors were located at the National Institute of Standards and Technology (NIST) and one was placed at Oak Ridge National Laboratory. For each HPGe detector, the detector response was modeled using the Gamma Detector Response Analysis Software (GADRAS) developed by Sandia National Laboratory. A set of NIST traceable sources, emitting gamma-rays between $60 \mathrm{keV}$ and $2.6 \mathrm{MeV}$, were used to build the detector response function using GADRAS and to determine the full-energy-peak efficiency for each detector. The DU source consist of a plate with a surface Area $\approx 103.23 \mathrm{~cm}^{2}(\approx 10.16 \times 10.16 \mathrm{~cm})$, and a thickness $\approx 0.32 \mathrm{~mm}$ (approximately $630 \mathrm{~g}$ ). The DU fluence rate measured by the three different HPGe detectors using the full-energy-peak efficiency for the $1001 \mathrm{keV}$ line was 0.4576 photons $/ \mathrm{s} / \mathrm{cm}^{2}( \pm 8.5 \%)$, 0.4386 photons $/ \mathrm{s} / \mathrm{cm}^{2}( \pm 3.9 \%)$ and 0.4467 photons $/ \mathrm{s} / \mathrm{cm}^{2}( \pm 5.0 \%)$. All uncertainties have a coverage factor, $k$, of 1 . 
Based on these three measured fluence rate measurements testing using the BRD-2 and BRD-3 were performed at 3 distances in order to obtain a fluence rate at the reference point of the BRDs of 0.22 photons $/ \mathrm{s} / \mathrm{cm}^{2}$ as specified in the RIIDs TCS. Measurements were performed at $1.2 \mathrm{~m} / \mathrm{s}$ and $2.2 \mathrm{~m} / \mathrm{s}, 10$ trials for each speed and distance. For the BRD-3 the number of alarms was recorded (due to the type of the BRD-3 display). For the BRD-2 the count rate, radiation level and radionuclides identified were recorded, the background radiation level for BRD-2 was approximately $230 \mathrm{cps}$, results are shown in Table 10 and Table 11. For the BRD-2 additional static measurements were performed to determine the response to this DU source, results are summarized in Table 12. From these dynamic measurements it can be observed that the fluence rate for the DU source specified in the RIIDs TCS is barely detectable by the BRDs.

Table 10: BRD-2 dynamic test results for DU plate measurements

\begin{tabular}{|l|c|c|c|c|l|l|}
\hline Radionuclide & $\begin{array}{c}\text { Distance } \\
(\mathbf{m})\end{array}$ & $\begin{array}{c}\text { Speed } \\
(\mathbf{m} / \mathbf{s})\end{array}$ & $\begin{array}{c}\text { Phantom } \\
(\mathbf{Y} / \mathbf{N})\end{array}$ & $\begin{array}{c}\text { Average net } \\
\text { gamma-ray } \\
\text { count rate } \\
(\mathbf{c p s})\end{array}$ & $\begin{array}{c}\text { Average } \\
\text { gamma- } \\
\text { ray level }\end{array}$ & $\begin{array}{c}\text { Radionuclides } \\
\text { Identified }\end{array}$ \\
\hline DU plate & 1.55 & 1.2 & $\mathrm{~N}$ & 92.2 & 3.9 & No ID (9), ?(1) \\
\hline DU plate & 1.55 & 2.2 & $\mathrm{~N}$ & 71.4 & 3.4 & No ID (10) \\
\hline DU plate & 1.83 & 1.2 & $\mathrm{~N}$ & 78.1 & 3 & No ID (10) \\
\hline DU plate & 1.83 & 2.2 & $\mathrm{~N}$ & 60.7 & 2.9 & No ID (10) \\
\hline DU plate & 2.29 & 1.2 & $\mathrm{~N}$ & 55.7 & 2.2 & No ID (10) \\
\hline DU plate & 2.29 & 2.2 & $\mathrm{~N}$ & 39.1 & 1.9 & No ID (10) \\
\hline
\end{tabular}

Table 11: BRD-3 dynamic test results for DU plate measurements

\begin{tabular}{|l|c|c|c|c|}
\hline Radionuclide & $\begin{array}{c}\text { Distance } \\
(\mathbf{m})\end{array}$ & $\begin{array}{c}\text { Speed } \\
(\mathbf{m} / \mathbf{s})\end{array}$ & $\begin{array}{c}\text { Phantom } \\
(\mathbf{Y} / \mathbf{N})\end{array}$ & $\begin{array}{c}\text { Number of } \\
\text { gamma-ray } \\
\text { alarms }\end{array}$ \\
\hline DU plate & 1.55 & 1.2 & $\mathrm{~N}$ & 0 \\
\hline DU plate & 1.55 & 2.2 & $\mathrm{~N}$ & 0 \\
\hline DU plate & 1.83 & 1.2 & $\mathrm{~N}$ & 0 \\
\hline DU plate & 1.83 & 2.2 & $\mathrm{~N}$ & 1 \\
\hline DU plate & 2.29 & 1.2 & $\mathrm{~N}$ & 0 \\
\hline DU plate & 2.29 & 2.2 & $\mathrm{~N}$ & 0 \\
\hline
\end{tabular}

Table 12: BRD-2 static test results for DU plate measurements

\begin{tabular}{|l|c|c|c|c|c|c|l|}
\hline Radionuclide & $\begin{array}{c}\text { Distance } \\
(\mathbf{m})\end{array}$ & $\begin{array}{c}\text { Speed } \\
(\mathbf{m} / \mathbf{s})\end{array}$ & $\begin{array}{c}\text { Phantom } \\
(\mathbf{Y} / \mathbf{N})\end{array}$ & $\begin{array}{c}\text { Net average } \\
\text { gamma-ray } \\
\text { count rate } \\
(\mathbf{c p s})\end{array}$ & $\begin{array}{c}\text { Unc. } \\
(\mathbf{\%})\end{array}$ & $\begin{array}{c}\text { Average } \\
\text { gamma- } \\
\text { ray level }\end{array}$ & Radionuclides Identified \\
\hline DU plate & 1.55 & 0 & $\mathrm{~N}$ & 225.4 & 1.29 & 6 & K-40 Norm 99, U-238 Norm 99. \\
\hline DU plate & 1.83 & 0 & $\mathrm{~N}$ & 186.2 & 3.19 & 5 & K-40 Norm 100, U-238 Norm 97. \\
\hline DU plate & 2.29 & 0 & $\mathrm{~N}$ & 118.1 & 2.90 & 4 & K-40 Norm 100, U-238 Norm 97. \\
\hline
\end{tabular}

A 1-Dimensional model (1-D model) was created for the DU plate using GADRAS. For two of the HPGe detectors, the measured count rate for the $1001 \mathrm{keV}$ line was compared to the value obtained using GADRAS. For the NIST detector, the measured count rate was $0.723 \mathrm{cps}$ and the 
calculated one was $0.684 \mathrm{cps}$, this corresponds to a percent difference of $-5.4 \%$. For the ORNL detector, the measured count rate was $1.3 \mathrm{cps}$ and the calculated one was $1.4 \mathrm{cps}$, this corresponds to a percent difference of $7.7 \%$. From these calculations it can be observed that source modeling is a usable tool (within approximately $\pm 12 \%$ ) to predict emissions from different DU source geometries.

Two additional 1-D models were created to compare the emission of one DU plate with that of two DU plates and a $4.5 \mathrm{~kg}$ DU sphere. The calculated count rate for the two DU plates was 1.2 cps and for the $4.5 \mathrm{~kg}$ DU sphere was $0.756 \mathrm{cps}$, see Figure 20.

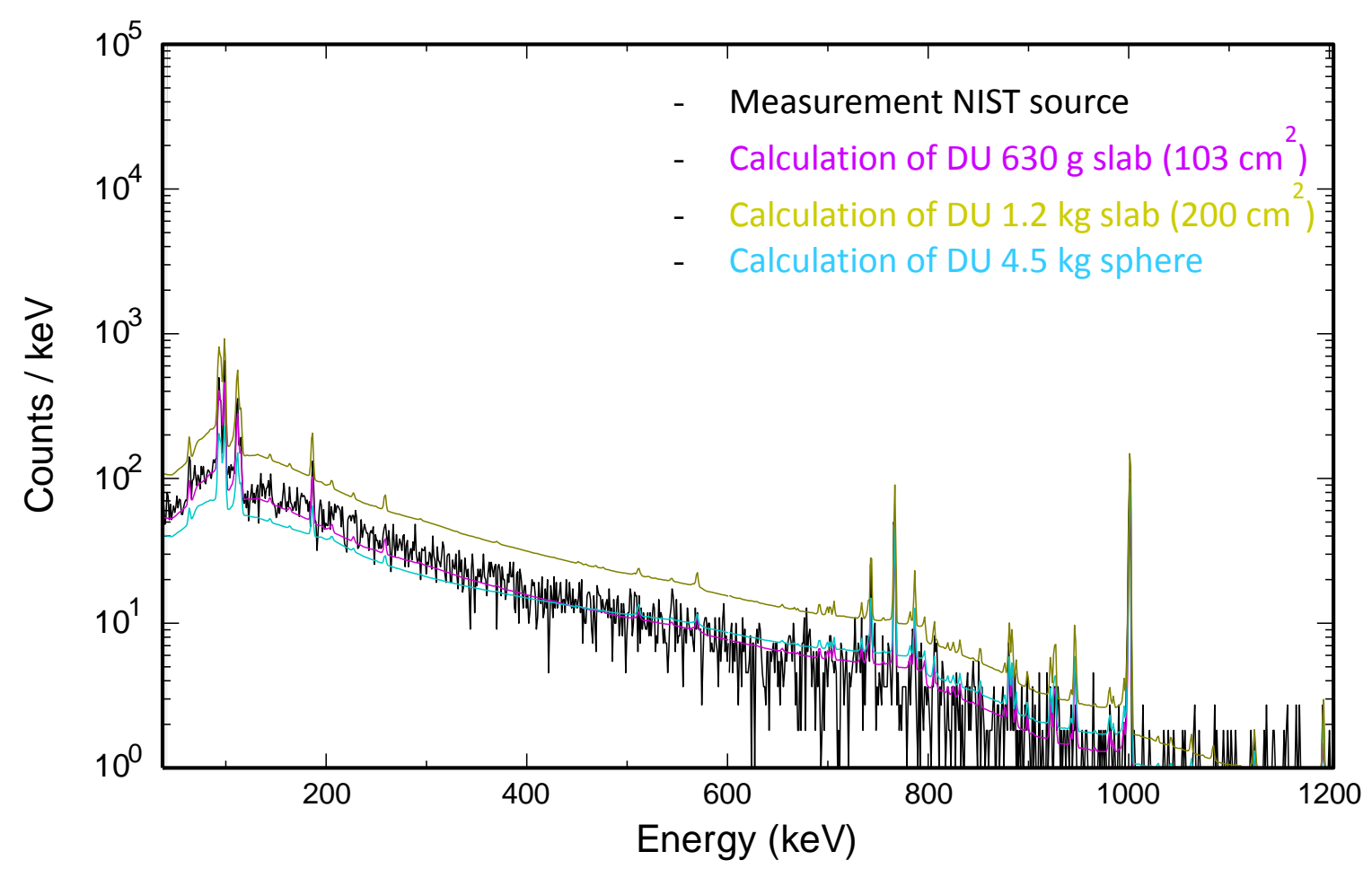

Figure 20: DU plate measurement graphed together with GADRAS 1-D models for two DU plates and one sphere

The DU, HEU and WGPu sources used by ORNL were measured using an HPGe detector. The gamma-ray emission rate and the testing distance to obtain the RIIDs TCS fluence rates were calculated using the measured HPGe full-energy-peak efficiency, results are shown in Table 13. This table also shows the fluence rate produce by the sources at a distance of $1 \mathrm{~m}$. These sources are going to be used in the future by ORNL to measure the BRD response under different test conditions specified in the TCSs.

A 1-Dimensional model (1-D model) was created for the sources specified in the DNDO traceability memo using GADRAS. From the model for each of the sources the emission rate and the expected testing distances for the RIIDs TCS fluence rates were calculated. For these calculations, GADRAS makes use of the following densities for uranium and plutonium: uranium $-18.95 \mathrm{~g} / \mathrm{cm}^{3}$, and plutonium (delta) $-15.75 \mathrm{~g} / \mathrm{cm}^{3}$. In addition calculated values 
provided by Los Alamos National Laboratory (LANL) are reported. These calculations used a density for uranium of $18.861 \mathrm{~g} / \mathrm{cm}^{3}$ and for plutonium of $16.9 \mathrm{~g} / \mathrm{cm}^{3}$. Results are shown in Table 14. The difference between the calculated LANL and GADRAS emission rate values are within $9 \%$, that is within the $\pm 12 \%$ estimated uncertainty of the GADRAS calculations.

Table 13: Emission rate calculations for ORNL sources

\begin{tabular}{|c|c|c|c|c|c|c|}
\hline $\begin{array}{l}\text { ORNL } \\
\text { Source }\end{array}$ & $\begin{array}{c}\text { Energy } \\
(\mathrm{keV})\end{array}$ & $\begin{array}{c}\text { Emission rate } \\
\text { (gammas/s) }\end{array}$ & $\begin{array}{c}\text { unc }(\%) \\
(k=1)\end{array}$ & $\begin{array}{c}\text { Fluence rate } \\
\left.\text { (photons } / \mathrm{s} / \mathrm{cm}^{2}\right) \\
\text { at } 1 \mathrm{~m}\end{array}$ & $\begin{array}{c}\text { Fluence rate } \\
\text { (photons } / \mathrm{s} / \mathrm{cm}^{2} \text { ) } \\
\text { RIIDs TCS } \\
\text { requirement }\end{array}$ & $\begin{array}{c}\text { Testing } \\
\text { Distance } \\
\text { (cm) }\end{array}$ \\
\hline \multirow{2}{*}{ DU 1 plate } & \multirow{2}{*}{1001} & \multirow{2}{*}{$4.15 \times 10^{4}$} & \multirow{2}{*}{7.0} & \multirow{2}{*}{0.33} & 0.22 & 123 \\
\hline & & & & & 3.9 & 29 \\
\hline \multirow{2}{*}{ DU 4 plates } & \multirow{2}{*}{1001} & \multirow{2}{*}{$1.69 \times 10^{5}$} & \multirow{2}{*}{3.0} & \multirow{2}{*}{1.35} & 0.22 & 247 \\
\hline & & & & & 3.9 & 59 \\
\hline \multirow{2}{*}{ HEU } & \multirow{2}{*}{186} & \multirow{2}{*}{$5.66 \times 10^{5}$} & \multirow{2}{*}{2.0} & \multirow{2}{*}{4.50} & 0.68 & 257 \\
\hline & & & & & 1.6 & 169 \\
\hline \multirow{2}{*}{ WGPu } & \multirow{2}{*}{414} & \multirow{2}{*}{$5.50 \times 10^{4}$} & \multirow{2}{*}{9.0} & \multirow{2}{*}{0.47} & 1.1 & 52 \\
\hline & & & & & 3.8 & 28 \\
\hline \multirow{2}{*}{$\begin{array}{c}\text { WGPu } \\
\text { shielded } \\
5 \mathrm{~mm} \text { steel }\end{array}$} & \multirow{2}{*}{414} & \multirow{2}{*}{$3.90 \mathrm{E} \times 10^{4}$} & \multirow{2}{*}{4.0} & \multirow{2}{*}{0.31} & 1.1 & 53 \\
\hline & & & & & 3.8 & 29 \\
\hline
\end{tabular}

Table 14: Emission rates and distance calculations for the RIIDs TCS fluence rates for traceability memo sources

\begin{tabular}{|l|c|c|c|c|c|}
\hline \multirow{2}{*}{$\begin{array}{c}\text { Traceability Memo } \\
\text { Sources }\end{array}$} & $\begin{array}{c}\text { Energy } \\
(\mathbf{k e V})\end{array}$ & $\begin{array}{c}\text { GADRAS } \\
\text { calculated } \\
\text { emission rate } \\
\text { (gammas/s) }\end{array}$ & $\begin{array}{c}\text { LANL calculated } \\
\text { emission rate } \\
\text { (gammas/s) }\end{array}$ & $\begin{array}{c}\text { Emission rate } \\
\text { (gammas/s) }\end{array}$ & Distance (m) \\
\hline $1 \mathrm{~kg} \mathrm{HEU}$ & 186 & $4.70 \times 10^{5}$ & $4.62 \times 10^{5}$ & 0.68 & 2.35 \\
\hline $400 \mathrm{~g} \mathrm{WGPu} \mathrm{(delta)}$ & 414 & $1.15 \times 10^{6}$ & $1.06 \times 10^{6}$ & 1.6 & 1.53 \\
\cline { 4 - 6 } & & & & 3.8 & 1.5 \\
\hline
\end{tabular}

Measurements were performed using ${ }^{57} \mathrm{Co}$ and ${ }^{133} \mathrm{Ba}$ as simulants for the HEU and WGPu sources. The ${ }^{57} \mathrm{Co}$ and ${ }^{133} \mathrm{Ba}$ sources were producing a fluence rate of 0.68 photons $/ \mathrm{s} / \mathrm{cm}^{2}$ and 1.1 photons $/ \mathrm{s} / \mathrm{cm}^{2}$ respectively. These sources were used to test the BRD-2 and BRD-3. These fluence rate values are consistent with the HEU and WGPu Conveyances/Pedestrians Category requirements in the RIIDs TCS. For these measurements the following sources were used:

- $677 \mathrm{kBq}(18.3 \mu \mathrm{Ci} \pm 5 \%, 1$-standard deviation $){ }^{57} \mathrm{Co}$ source placed at a distance of $2.62 \mathrm{~m}$ from the reference point of the BRD

- $507 \mathrm{kBq}(13.7 \mu \mathrm{Ci} \pm 5 \%, 1$-standard deviation $){ }^{133} \mathrm{Ba}$ source placed at a distance of $2.22 \mathrm{~m}$ from the reference point of the BRD.

Static measurements were also performed using ${ }^{57} \mathrm{Co}$ and ${ }^{133} \mathrm{Ba}$ producing a fluence rate of 0.18 photons $/ \mathrm{s} / \mathrm{cm}^{2}$ and 0.3 photons $/ \mathrm{s} / \mathrm{cm}^{2}$ respectively using BRD-1 and BRD-2. These fluence rate values match the HEU and WGPu Containerized Cargo Category requirements in the RIIDs 
TCS. For these measurements the same ${ }^{57} \mathrm{Co}$ and ${ }^{133} \mathrm{Ba}$ sources were used, placed at a distance of $4.3 \mathrm{~m}$ and $4.2 \mathrm{~m}$ from the BRD respectively.

The sources were moved passed the BRD at a speed of $1.2 \mathrm{~m} / \mathrm{s}$ and $2.2 \mathrm{~m} / \mathrm{s}$ without the presence of a phantom for total of 10 trials for each source and speed. The background count rate as measured by the BRD was approximately $230 \mathrm{cps}$. The results of the measurements are summarized in Table 15 and Table 16. In Table 15 the number in parenthesis next to the radionuclides identified represents the number of trials for which this identification as displayed by the BRD. The results of the static measurement using the BRD-1 and BRD-2 are summarized in Table 17 and Table 18. For the static measurements the radionuclides recorded were those displayed by the BRD in the main screen (automatically updated radionuclide identification). From these measurements it can be observed that sources producing these fluence rates are close to the limit of detection and identification for the BRDs.

Table 15: Results of BRD-2 dynamic measurements for ${ }^{57} \mathrm{Co}$ and ${ }^{133} \mathrm{Ba}$ source

\begin{tabular}{|l|c|c|c|c|c|c|l|}
\hline \multicolumn{1}{|c|}{ Source } & $\begin{array}{c}\text { Distance } \\
(\mathbf{m})\end{array}$ & $\begin{array}{c}\text { Speed } \\
(\mathbf{m} / \mathbf{s})\end{array}$ & $\begin{array}{c}\text { Phantom } \\
(\mathbf{Y} / \mathbf{N})\end{array}$ & $\begin{array}{c}\text { Average net } \\
\text { gamma-ray } \\
\text { count rate (cps) }\end{array}$ & $\begin{array}{c}\text { Std dev } \\
(\mathbf{\%})\end{array}$ & $\begin{array}{c}\text { Average } \\
\text { gamma- } \\
\text { ray level }\end{array}$ & $\begin{array}{c}\text { Radionuclides } \\
\text { Identified }\end{array}$ \\
\hline${ }^{133} \mathrm{Ba}$ & 2.22 & 1.2 & $\mathrm{~N}$ & 85.7 & 2.68 & 2.9 & $\mathrm{Ba}-133(6), \mathrm{No}$ ID (4) \\
\hline${ }^{133} \mathrm{Ba}$ & 2.22 & 2.2 & $\mathrm{~N}$ & 70.6 & 2.65 & 2.7 & $\mathrm{Ba}-133(2), \mathrm{No}$ ID (8) \\
\hline${ }^{57} \mathrm{Co}$ & 2.62 & 1.2 & $\mathrm{~N}$ & 50 & 2.21 & 3 & $\mathrm{Co}-57(10)$ \\
\hline${ }^{57} \mathrm{Co}$ & 2.62 & 2.2 & $\mathrm{~N}$ & 42.3 & 3.44 & 2 & $\mathrm{Co}-57(8)$, No ID (2) \\
\hline
\end{tabular}

Table 16: Results of BRD-3 dynamic measurements for ${ }^{57} \mathrm{Co}$ and ${ }^{133}$ Ba source

\begin{tabular}{|l|c|c|c|c|c|}
\hline \multicolumn{1}{|c|}{ Source } & $\begin{array}{c}\text { Distance } \\
(\mathbf{m})\end{array}$ & $\begin{array}{c}\text { Speed } \\
(\mathbf{m} / \mathbf{s})\end{array}$ & $\begin{array}{c}\text { Phantom } \\
(\mathbf{Y} / \mathbf{N})\end{array}$ & $\begin{array}{c}\text { Number of } \\
\text { gamma-ray } \\
\text { alarms }\end{array}$ & $\begin{array}{c}\text { Average gamma- } \\
\text { ray level }\end{array}$ \\
\hline${ }^{133} \mathrm{Ba}$ & 2.22 & 1.2 & $\mathrm{~N}$ & 5 & $\mathrm{NA}$ \\
\hline${ }^{133} \mathrm{Ba}$ & 2.22 & 2.2 & $\mathrm{~N}$ & 4 & $\mathrm{NA}$ \\
\hline${ }^{57} \mathrm{Co}$ & 2.62 & 1.2 & $\mathrm{~N}$ & 1 & $\mathrm{NA}$ \\
\hline${ }^{57} \mathrm{Co}$ & 2.62 & 2.2 & $\mathrm{~N}$ & 0 & $\mathrm{NA}$ \\
\hline
\end{tabular}

Table 17: Results of BRD-1 static measurements for ${ }^{57} \mathrm{Co}$ and ${ }^{133}$ Ba source

\begin{tabular}{|l|c|c|c|c|c|}
\hline Source & $\begin{array}{c}\text { Distance } \\
(\mathbf{m})\end{array}$ & $\begin{array}{c}\text { Speed } \\
(\mathbf{m} / \mathbf{s})\end{array}$ & $\begin{array}{c}\text { Net average } \\
\text { gamma-ray } \\
\text { count rate }(\mathbf{c p s})\end{array}$ & $\begin{array}{c}\text { Std dev } \\
(\boldsymbol{\%})\end{array}$ & $\begin{array}{c}\text { BRD average } \\
\text { gamma-ray } \\
\text { level }\end{array}$ \\
\hline${ }^{133} \mathrm{Ba}$ & 4.2 & 0 & 27 & 33 & 1 \\
\hline${ }^{57} \mathrm{Co}$ & 4.3 & 0 & 16 & 35 & 1 \\
\hline
\end{tabular}


Table 18: Results of BRD-2 static measurements for ${ }^{57} \mathrm{Co}$ and ${ }^{133} \mathrm{Ba}$ source

\begin{tabular}{|l|c|c|c|c|c|l|}
\hline Source & $\begin{array}{c}\text { Distance } \\
(\mathbf{m})\end{array}$ & $\begin{array}{c}\text { Speed } \\
(\mathbf{m} / \mathbf{s})\end{array}$ & $\begin{array}{c}\text { Net average } \\
\text { gamma-ray } \\
\text { count rate }(\mathbf{c p s})\end{array}$ & $\begin{array}{c}\text { Std dev } \\
(\boldsymbol{\%})\end{array}$ & $\begin{array}{c}\text { BRD average } \\
\text { gamma-ray } \\
\text { level }\end{array}$ & \multicolumn{1}{|c|}{ Radionuclides Identified } \\
\hline${ }^{133} \mathrm{Ba}$ & 2.22 & 0 & 127.6 & 3 & 4.5 & Ba-133 Ind 100, K-40 Norm 97. \\
\hline${ }^{57} \mathrm{Co}$ & 2.62 & 0 & 71.9 & 10 & 3.5 & K-40 Norm 99, Co-57 Ind 93. \\
\hline${ }^{133} \mathrm{Ba}$ & 4.2 & 0 & 56 & 5 & 1.5 & Ba-133 (display intermetent) \\
\hline${ }^{57} \mathrm{Co}$ & 4.3 & 0 & 7 & 15 & 0.5 & Co-57 (display intermetent) \\
\hline
\end{tabular}

The fluence rates specified in the BRD TCS for HEU 0.94 photons $/ \mathrm{s} / \mathrm{cm}^{2}, \mathrm{WGPu}$ 2.3 photons $/ \mathrm{s} / \mathrm{cm}^{2}$ and DU 0.34 photons $/ \mathrm{s} / \mathrm{cm}^{2}$ were also used to test the BRDs. For these measurements the following sources were used:

- $440 \mathrm{kBq}(11.9 \mu \mathrm{Ci} \pm 5 \%, 1$-standard deviation $){ }^{57} \mathrm{Co}$ source placed at a distance of $1.94 \mathrm{~m}$ from the reference point of the BRD

- $\quad 492 \mathrm{kBq}(13.3 \mu \mathrm{Ci} \pm 5 \%, 1$-standard deviation $){ }^{133} \mathrm{Ba}$ source placed at a distance of $1.55 \mathrm{~m}$ from the reference point of the BRD

- DU plate placed at a distance of $1.13 \mathrm{~m}$ from the reference point of the BRD

The sources were moved passed the BRD at a speed of $1.2 \mathrm{~m} / \mathrm{s}$ without the presence of a phantom for total of 10 trials for each source and speed. The results of these measurements are plotted together with the TCS fluence rate values used for RIIDs testing, see Figure 21 and Figure 22. There seems to be an observable variation in the BRD-2 response for the different fluence rate values. The results of these measurements for all the BRDs are shown in Figure 23. From Figure 23 it can be observed that BRD-3 barely alarmed to all 3 sources. The fluence rates specified in the BRD TCS for HEU, WGPu and DU are above the detection limits for two of the BRDs. 


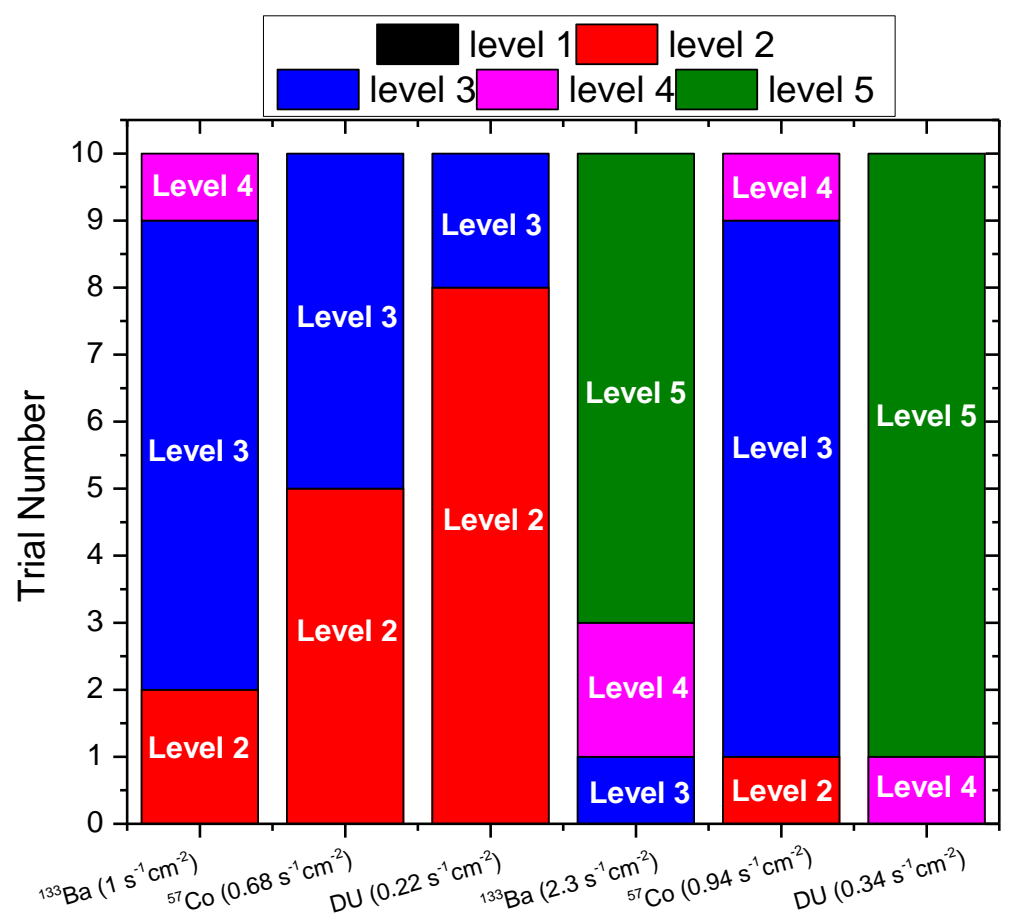

Source

Figure 21: BRD-2 level indication for different fluence rate values without PMMA phantom, source speed $1.2 \mathrm{~m} / \mathrm{s}$. The fluence rates (in units of photons $/ \mathrm{s} / \mathrm{cm}^{2}$ ) are given in parenthesis.

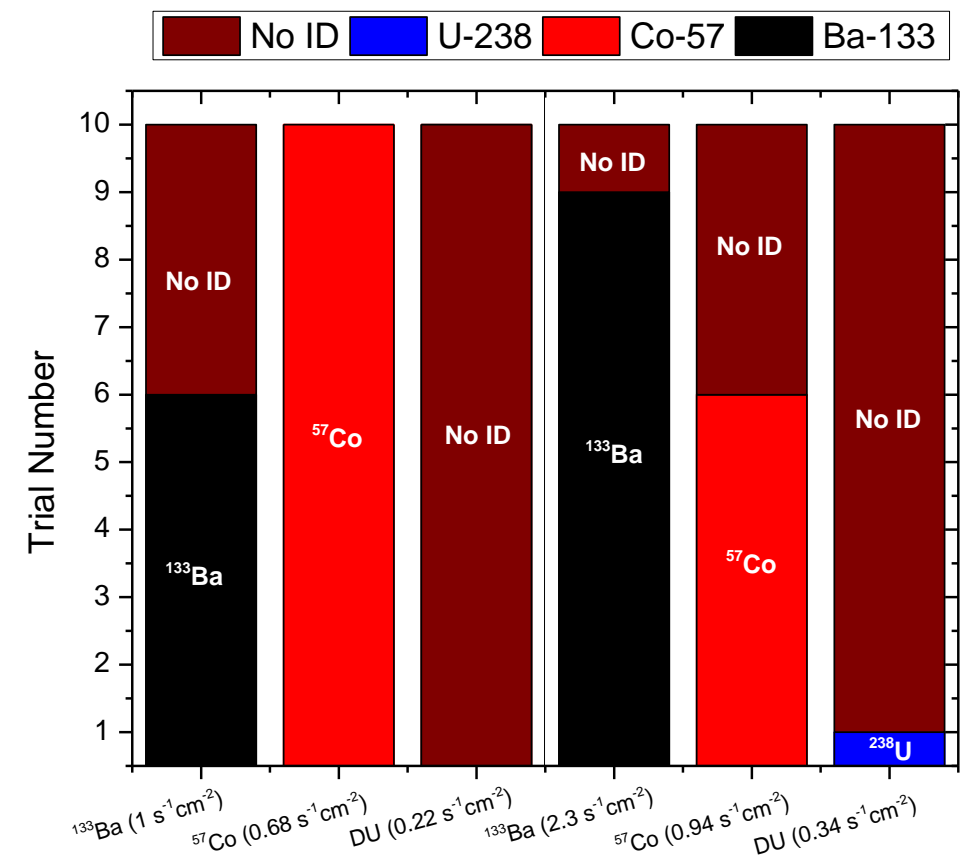

Source

Figure 22: BRD-2 radionuclide identification indication for different fluence rate values without PMMA phantom, source speed $1.2 \mathrm{~m} / \mathrm{s}$ 


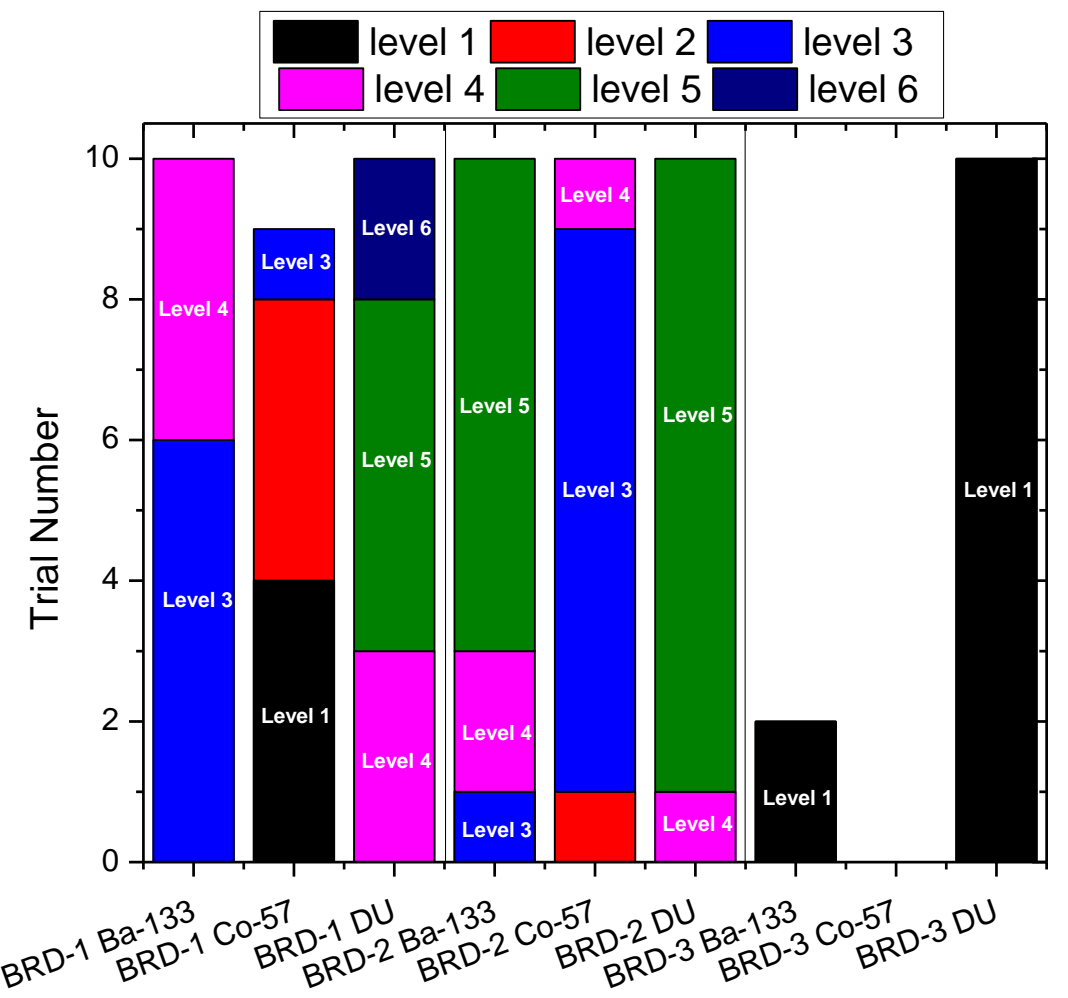

Figure 23: Level indication for the BRD TCS fluence rate values (HEU 0.94 photons $/ \mathrm{s} / \mathrm{cm}^{2}$, WGPu $2.3 \mathrm{photons} / \mathrm{s} / \mathrm{cm}^{2}$ and DU 0.34 photons $/ \mathrm{s} / \mathrm{cm}^{2}$ ) for all the BRDs without PMMA phantom, source speed $1.2 \mathrm{~m} / \mathrm{s}$

\subsection{Neutron measurement requirements}

The BRD TCS does not include neutron detection as neutron testing is performed in the ANSI/IEEE N42.53 standard for BRDs. Discussions took place in the TCS working group meetings regarding neutron testing to ensure that the ANSI/IEEE N42.53 requirements are sufficient for this type of instruments. The ANSI/IEEE N42.53 requires testing with a ${ }^{252} \mathrm{Cf}$ source surrounded by $1 \mathrm{~cm}$ steel and $0.5 \mathrm{~cm}$ lead that has an emission rate of $20,000 \mathrm{n} / \mathrm{s}( \pm 20 \%$, 1 -standard deviation) moving at $1.2 \mathrm{~m} / \mathrm{s}$ at a distance of 1.5 meters (source to reference point) unmoderated and moderated by a $4 \mathrm{~cm}$ thick HDPE sphere

The BRD-2 was used to assess the neutron response. The two ${ }^{252} \mathrm{Cf}$ sources listed in Table 1 were used for these measurements. The $2 \times 10^{4}$ neutrons $/ \mathrm{s}{ }^{252} \mathrm{Cf}$ source was shielded by $1 \mathrm{~cm}$ of steel, the gamma-ray emission of this source was very low so there was no need to add the lead shielding for the neutron tests. While the $4.2 \times 10^{5}$ neutrons $/ \mathrm{s}{ }^{252} \mathrm{Cf}$ source was considered a bare source; it was placed inside a $0.762 \mathrm{~mm}$ thick aluminum holder. The sources were placed at the same height as the center of the BRD and at $1.5 \mathrm{~m}$ from the front face of the BRD. The average neutron background at the test location measured using the BRD-2 was $2.7 \mathrm{cps} \pm 34 \%$. The average neutron background at the same location using the Thermo Eberline ASP 2e neutron handheld survey meter was $0.06 \mathrm{cps} \pm 57 \%$ (integrated over different times ranging from 2 to 6 $\min )$. 
The large neutron source $\left(4.2 \times 10^{5}\right.$ neutrons/s $)$ was used to determine the BRD-2 neutron count rate response as a function of moderator thickness with and without the presence of PMMA phantoms, see Figure 24. From this figure it can be observed that the maximum BRD-2 neutron response is obtained when the source is moderated by $2 \mathrm{~cm}$ or $4 \mathrm{~cm}$ thick HDPE spheres when the PMMA phantom is located behind the BRD.

The smaller unmoderated neutron source $\left(2 \times 10^{4}\right.$ neutrons/s $)$ was used to determine the BRD-2 neutron count rate response for different types of phantoms, see Figure 25. From this figure a slight increase in response is observed when the PMMA phantom or the water placed in the high position (centered in the BRD) is placed behind the BRD-2. The results of these measurements are statistically indistinguishable due to the large uncertainties in the measurements.

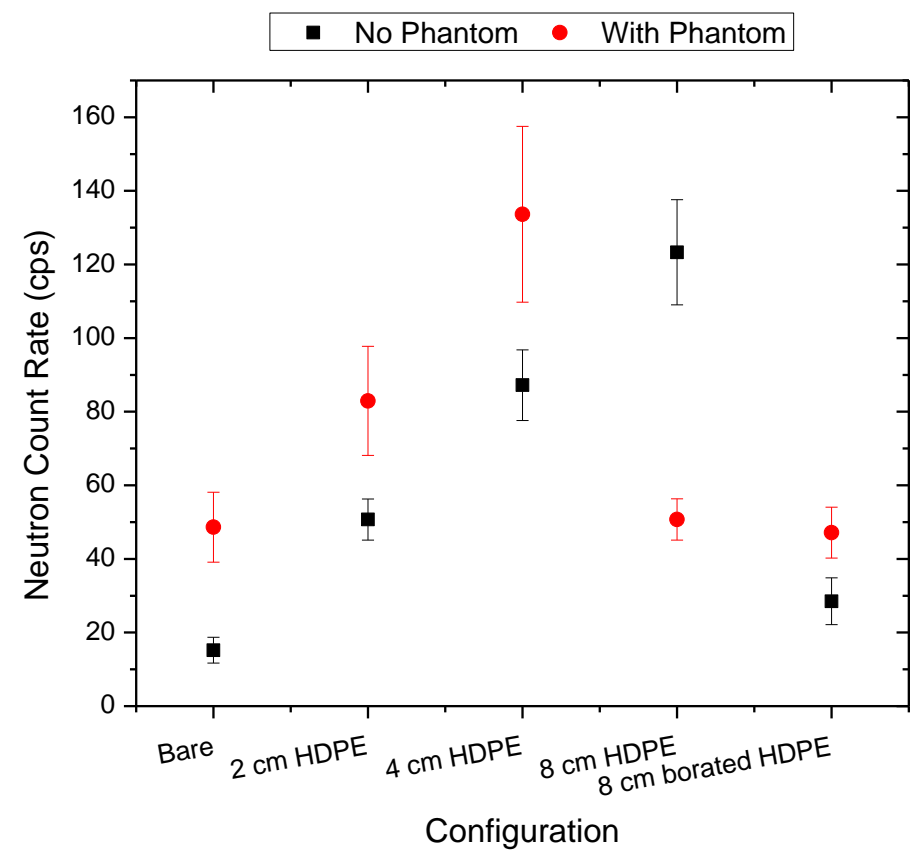

Figure 24: Neutron BRD-2 measurements with different moderators with and without the presence of a phantom; uncertainties are 1-standard deviation 


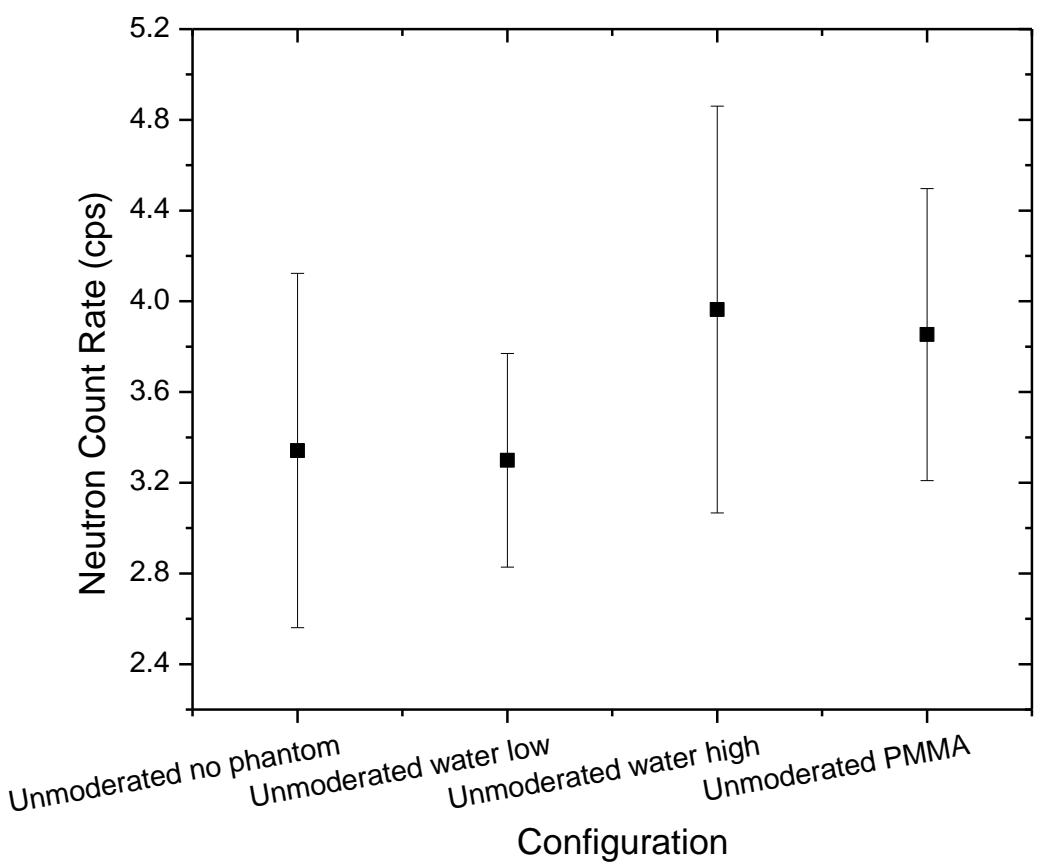

Figure 25: Unmoderated neutron BRD-2 measurements for different phantoms; uncertainties are 1-standard deviation.

The smaller unmoderated neutron source $\left(2 \times 10^{4}\right.$ neutrons/s) was used to determine the BRD-1, BRD-2 and BRD-3 neutron response for different source speeds with different phantoms, results are shown in 
Table 19 through Table 21 assesses the applicability of the ANSI N42.53 requirements. Ten trials were performed for each test condition for each BRD at a distance of $1.5 \mathrm{~m}$ from the source. The neutron background readings for the different BRDs were as follow:

- For BRD-1 and BRD-2 the neutron background level was equal to 0. For the BRD-1 the average neutron background count rate reading was $0.64 \mathrm{cps}( \pm 20 \%, 1$-standard deviation).

- For the BRD-3 the neutron background level varied between level 0 and 1 . For the BRD3 the average neutron background count rate reading was $3.1 \mathrm{cps}( \pm 30 \%, 1$-standard deviation).

The response for the BRD-1 was also obtained for static measurements as this BRD shows a gamma-ray response to the neutron source. The static measurements allow the quantification of this effect. The results of these measurements are shown inTable 22. From these tables it can be observed that the ${ }^{252} \mathrm{Cf}$ source with an emission rate of $2 \times 10^{4}$ neutrons/s is barely detectable by all BRDs especially for BRD-2. 
Table 19: Neutron dynamic measurement for BRD-1 at $1.5 \mathrm{~m}$ for the $2 \times 10^{4}$ neutrons/s source

\begin{tabular}{|c|c|c|c|c|c|c|c|c|c|}
\hline $\begin{array}{c}\text { Speed } \\
(\mathbf{m} / \mathbf{s})\end{array}$ & Phantom & $\begin{array}{c}\text { Number } \\
\text { of } \\
\text { gamma- } \\
\text { ray } \\
\text { alarms }\end{array}$ & $\begin{array}{c}\text { Number } \\
\text { of } \\
\text { neutron } \\
\text { alarms }\end{array}$ & $\begin{array}{c}\text { Average } \\
\text { BRD-1 } \\
\text { gamma- } \\
\text { ray level }\end{array}$ & $\begin{array}{c}\text { Average } \\
\text { BRD-1 } \\
\text { neutron } \\
\text { level }\end{array}$ & $\begin{array}{c}\text { Average } \\
\text { BRD-1 } \\
\text { gamma-ray } \\
\text { net count } \\
\text { rate (cps) }\end{array}$ & Unc. (\%) & $\begin{array}{c}\text { Average } \\
\text { BRD-1 } \\
\text { neutron } \\
\text { net count } \\
\text { rate (cps) }\end{array}$ & Unc. (\%) \\
\hline 1.2 & PMMA & 3 & 9 & 0.6 & 2.5 & 37.8 & 30.5 & 0.97 & 22.6 \\
\hline 2.2 & PMMA & 2 & 9 & 0.4 & 2 & 36.6 & 31.6 & 0.87 & 26.5 \\
\hline 1.2 & None & 2 & 7 & 0.2 & 1.3 & 28.6 & 20.1 & 0.42 & 20.4 \\
\hline 2.2 & None & 3 & 8 & 0 & 0.9 & 32.4 & 21.2 & 0.41 & 23.5 \\
\hline
\end{tabular}

Table 20: Neutron dynamic measurements for BRD-2 at $1.5 \mathrm{~m}$ for the $2 \times 10^{4}$ neutrons/s source

\begin{tabular}{|c|c|c|}
\hline Speed $(\mathbf{m} / \mathbf{s})$ & Phantom & $\begin{array}{c}\text { Number of neutron } \\
\text { alarms BRD-2 }\end{array}$ \\
\hline 1.2 & None & 1 \\
\hline 2.2 & None & 0 \\
\hline 1.2 & Water & 1 \\
\hline 2.2 & Water & 0 \\
\hline 1.2 & PMMA & 3 \\
\hline 2.2 & PMMA & 3 \\
\hline
\end{tabular}

Table 21: Neutron dynamic measurements for BRD-3 at $1.5 \mathrm{~m}$ for the $2 \times 10^{4}$ neutrons/s source

\begin{tabular}{|c|c|c|c|c|c|c|c|c|c|}
\hline $\begin{array}{c}\text { Speed } \\
(\mathbf{m} / \mathbf{s})\end{array}$ & Phantom & $\begin{array}{c}\text { Number of } \\
\text { gamma-ray } \\
\text { alarms }\end{array}$ & $\begin{array}{c}\text { Number of } \\
\text { neutron } \\
\text { alarms }\end{array}$ & $\begin{array}{c}\text { Average } \\
\text { BRD-3 } \\
\text { gamma-ray } \\
\text { level }\end{array}$ & $\begin{array}{c}\text { Average } \\
\text { BRD-3 } \\
\text { neutron } \\
\text { level }\end{array}$ & $\begin{array}{c}\text { Average } \\
\text { BRD-3 } \\
\text { gamma- } \\
\text { ray net } \\
\text { count } \\
\text { rate (cps) }\end{array}$ & $\begin{array}{c}\text { Unc. } \\
(\%)\end{array}$ & $\begin{array}{c}\text { Average } \\
\text { BRD-3 } \\
\text { neutron } \\
\text { net count } \\
\text { rate (cps) }\end{array}$ & $\begin{array}{c}\text { Unc. } \\
(\%)\end{array}$ \\
\hline 1.2 & PMMA & 3 & 10 & 0.6 & 2.2 & 50.1 & 4.5 & 1.2 & 56 \\
\hline 2.2 & PMMA & 2 & 10 & 0.4 & 1.7 & 48.0 & 4.9 & 1.3 & 48 \\
\hline 1.2 & None & 0 & 9 & 0.0 & 1.3 & 56.7 & 5.0 & 1.6 & 34 \\
\hline 2.2 & None & 0 & 10 & 0.0 & 1.3 & 41.3 & 5.2 & 0.7 & 42 \\
\hline Uncertainties are 1-standard deviation.
\end{tabular}


Table 22: Neutron static measurement for BRD-1 at $1.5 \mathrm{~m}$

\begin{tabular}{|c|c|c|c|c|c|c|c|}
\hline $\begin{array}{c}\text { Neutron } \\
\text { emission rate } \\
\text { (neutrons/s) }\end{array}$ & Phantom & $\begin{array}{c}\text { Average } \\
\text { BRD-1 } \\
\text { gamma- } \\
\text { ray level }\end{array}$ & $\begin{array}{c}\text { Average } \\
\text { BRD-1 } \\
\text { neutron } \\
\text { level }\end{array}$ & $\begin{array}{c}\text { Average } \\
\text { BRD-1 } \\
\text { gamma- } \\
\text { ray gross } \\
\text { count rate } \\
\text { (cps) }\end{array}$ & Unc. $(\%)$ & $\begin{array}{c}\text { Average } \\
\text { BRD-1 } \\
\text { neutron } \\
\text { gross } \\
\text { count rate } \\
\text { (cps) }\end{array}$ & Unc. (\%) \\
\hline No Source & PMMA & - & - & 40 & 28.67 & 0.65 & 10.88 \\
\hline $2 \times 10^{4}$ & PMMA & 0.5 & 5.50 & 53.6 & 21.17 & 3.01 & 23.77 \\
\hline No Source & None & - & - & 45.78 & 23.57 & 0.8 & 35.36 \\
\hline $2 \times 10^{4}$ & None & 1 & 2.5 & 60.80 & 20.05 & 1.6 & 22.44 \\
\hline
\end{tabular}

\section{Conclusions}

Summarized below are the conclusions for each of the tests conducted in this study.

- Scaling of source emission with gamma-ray and neutron background measurement at test location

From the source scaling measurements it can be observed that the measurements of the gammaray and neutron radiation background have a large uncertainty and the measured value depends on the type of instrument used to perform the measurements. This could be an issue if the source emission is scaled with the radiation background when testing of BRDs is performed in different laboratories.

- BRD response as a function of increasing gamma-ray background level

The background increase measurements show a reduction of the BRD sensitivity with increasing gamma-ray dose rate. This issue can be solved by:

a) Reducing the background dose rate range over which testing can occur

b) Having a common instrument to measure background at different test locations allowing for scaling of the source emission at different test locations

- Suitability of fluence rate values used for testing BRDs

For the fluence rates specified in the TCS RIIDs Conveyances/Pedestrians Category for HEU 0.68 photons $/ \mathrm{s} / \mathrm{cm}^{2}$, WGPu 1.1 photons $/ \mathrm{s} / \mathrm{cm} 2$ and DU 0.22 photons $/ \mathrm{s} / \mathrm{cm}^{2}$ as well as those specified in the BRD TCS for HEU 0.94 photons $/ \mathrm{s} / \mathrm{cm}^{2}$, WGPu 2.3 photons $/ \mathrm{s} / \mathrm{cm}^{2}$ and DU 0.34 photons $/ \mathrm{s} / \mathrm{cm}^{2}$ were used to test the BRDs. There seems to be a small variation of the BRD-2 response when testing with ${ }^{57} \mathrm{Co}$ and ${ }^{133} \mathrm{Ba}$ sources for these different fluence rate values, either set of values seem adequate for testing the BRDs. If it is required to be closer to the detection limit of the BRDs, the fluence rate values could be further reduced. 
The fluence rates specified in the RIIDs Containerized Cargo Category for HEU 0.18 photons $/ \mathrm{s} / \mathrm{cm}^{2}$ and WGPu 0.3 photons $/ \mathrm{s} / \mathrm{cm}^{2}$ were also used for testing. These fluence rate values are acceptable for use and close to the limit of detection and identification of the BRDs.

The BRDs was able to detect the $90 \mathrm{mg}{ }^{237} \mathrm{~Np}$ source bare and shielded by $1 \mathrm{~cm}$ of steel at a $2 \mathrm{~m}$ and a $3 \mathrm{~m}$ distance. The radiation detection level was reduced by the presence of the steel shielding. For these measurements it was observed that the testing distance for the shielded ${ }^{237} \mathrm{~Np}$ source can be increased to $3 \mathrm{~m}$ or larger if testing requires being closer to the detection limit of the BRDs.

- Calculations of emission rates and/or fluence rate for SNM and DU sources

From the SNM and DU measurements and calculations it can be observed that the GADRAS $1 \mathrm{D}$-model is a useful tool to determine the emission rate of an unknown source with an uncertainty of approximately $\pm 12 \%$.

- Neutron measurement requirements

From the neutron test results it can be observed that the ${ }^{252} \mathrm{Cf}$ source emission specified in the ANSI/IEEE N42.53 standard is close to the limit of detection for the BRDs used in these tests. The addition of moderator to the ${ }^{252} \mathrm{Cf}$ source increases the probability of detection for the BRD. The use of phantoms increases the probability of detection for the BRD. The presence of a phantom is required to mimic the presence of a human body. There seems to be a small variation in response depending on the type of phantom used for testing. It is important to define the material and dimensions of the phantom used for testing in order to have reproducible results at different test locations.

\section{Acknowledgments}

The authors would like to thank the Department of Homeland Security (DHS) Domestic Nuclear Detection Office (DNDO) for funding this work. The authors would also like to thank Mr. Jason Combs from Oak Ridge National Laboratory for providing the gamma-ray energy spectra for some of their sources. The authors would also like to thank Dr. Ronaldo Minniti from NIST for providing the information on the radiation background measurements using several ionization chambers.

\section{References}

1. ANSI/IEEE N42.53 American National Standard Performance Criteria for Backpack Based Radiation Detection Systems Used for Homeland Security

2. Technical Capability Standard for Handheld Instruments Used for the Detection and Identification of Radionuclides, Document Number: 500-DNDO-117250v0.00 (2011), http://www.dhs.gov/xlibrary/assets/dndo/dndo-technical-capability-standard-forhandheld-final.pdf 
3. Technical Capability Standards, Traceability Memo, September 2012, Document Number 500-DNDO-119600v1.1

4. ANSI/IEEE N42.43 American National Standard Performance Criteria for Mobile and Transportable Radiation Monitors Used for Homeland Security

5. L. Pibida. "Measurements for the Development of a Simulated Naturally Occurring Radioactive Material" Journal of Research of the National Institute of Standards and Technology, Volume 117 (2012) (http://dx.doi.org/10.6028/jres.117.008)

6. Laboratoire National Henri Becquerel (LNHB), Recommended Data, http://www.nucleide.org/DDEP_WG/DDEPdata.htm

7. The physics of radiology, $4^{\text {th }}$ Edition, Publisher Charles C. Thomas. Authors: Harold Elford Johns and John Robert Cunningham. 